\title{
A COMPETENCE-BASED VIEW OF INDUSTRY EVOLUTION: THE IMPACT OF SUBMARKET CONVERGENCE ON INCUMBENT-ENTRANT DYNAMICS
}

\author{
BILGEHAN UZUNCA \\ Utrecht University
}

\begin{abstract}
Understanding intra-industry boundaries is important because it offers insight into firms' strategic options based on their competences. Defining intra-industry heterogeneity in terms of the technological and customer competences that are required to produce and sell different products in each submarket, this paper explores whether the convergence of these competences, i.e., an increase in the degree to which competences can be leveraged across submarkets, exerts differential effects on the success of industry incumbents versus entrants. Empirical evidence from the global semiconductor manufacturing industry shows that convergence in both technological and customer competences decreases entrants' survival chances, whereas a lack of convergence in any one of the two types of competence-that is, in one set of competences or another but not in both-gives entrants sufficient room to gain a foothold in the industry and to potentially disrupt incumbents. As a strategic response to disruption, multiplant industry incumbents can reposition themselves by changing their focus across submarkets while not necessarily exiting the industry entirely. The paper contributes to the literature on industry evolution, disruption, and competitive dynamics and has implications for future research and practice.
\end{abstract}

The relative fate of industry incumbents and entrants over the course of industry evolution has been a major topic of interest in the management literature (Agarwal, Sarkar, \& Echambadi, 2002; Christensen, 1997; King \& Tucci, 2002; Klepper, 1996; Tripsas, 1997). Earlier studies on industry evolution have documented primarily that industry incumbents have advantages over entrants because of the convergence toward homogeneous industry structures (Gort \&

I thank my Associate Editor Linus Dahlander, and three anonymous reviewers for providing highly constructive and useful feedback that allowed me to improve the manuscript substantially. I wish to acknowledge my thesis advisor, Prof. Bruno Cassiman, who guided and supported me throughout this study. I would like to also thank Dan Tracy, Senior Director of Industry Research and Statistics at Semiconductor Equipment and Materials International (SEMI ${ }^{\mathrm{TM}}$ ) for providing access to the World Fab Watch (WFW) dataset and his continued support throughout my research. I would also like to thank several people for their invaluable insights in helping me bring this research to fruition, including Nick Argyres, A. Andrew King, Hakan Özalp, Richard Priem, Coen Rigtering, Laura Reijnders, Lourdes Sosa, Brian Silverman, Erik Stam, and Fernando Suarez. Earlier versions of this paper have been presented at the 2013 AOM Annual Meeting in Orlando, FL, USA and the 2013 SMS Annual International Conference in Atlanta, GA, USA.
Klepper, 1982; Klepper, 1996; Utterback \& Abernathy, 1975). These studies have provided broad conceptual schemes, such as scale advantages in the mass production of standardized goods (Klepper, 1996) or the coalescence of an industry around a particular technology-dubbed a dominant design-among many competing alternative technologies (Anderson \& Tushman, 1990; Utterback \& Suarez, 1993), followed by the industry's consolidation into a stable oligopoly (through a shakeout) (Klepper, 1997). Because of the focus on convergence toward homogeneous industry structures, this traditional monolithic view of industry evolution often favors industry incumbents and suggests that later entrants have few or no opportunities for survival (Knudsen, Levinthal, \& Winter, 2014).

The industry evolution literature has gradually shifted to studying industries that persist as segmented and heterogeneous product markets that can offer opportunities for entrants (Adner, 2002; Argyres, Bigelow, \& Nickerson, 2015; Bhaskarabhatla \& Klepper, 2014; de Figueiredo \& Silverman, 2007; Klepper \& Thompson, 2006; King \& Tucci, 2002). By dividing industries into niches or submarkets, scholars have explored competitive accounts of disruptive technologies (Adner, 2002; Adner \& Zemsky, 2005), entry into new market niches (King \& Tucci, 2002), and the repositioning of 
incumbents (i.e., abandoning a segment) as a strategic response to industry change (Argyres et al., 2015; de Figueiredo \& Silverman, 2007). Further theoretical underpinning is nevertheless needed to account for variation in our understanding of intra-industry boundaries. Many industries feature striking levels of product variety that belie their limited Standard Industrial Classification (SIC) codes (Bryce \& Winter, 2009). These boundaries not only are a function of the distinct technical knowledge but also may derive from the demand environment, which has heterogeneous and changing consumer needs (Adner \& Levinthal, 2001; Tripsas, 2008). Moreover, to understand the continuous restructuring of intra-industry boundaries, we need to consider multiple submarkets coevolving within an industry (Klepper \& Thompson, 2006; Sutton, 1998), which recurrently shape firms' strategic options based on their competences. ${ }^{1}$ The existing literature has not focused on differentiating the competences needed in each submarket and, particularly, the convergence of these competences (i.e., an increase in the degree to which competences can be leveraged across submarkets). What we need is a theory that explains how the changes in the distinctiveness of submarkets within an industry affect the extent to which industry incumbents or entrants have the competences that are needed to compete in them. Only then can we understand competitive dynamics and industry evolution.

To fill this gap, in this study, I offer a competencebased view of industry evolution. I argue that to explain the selection process between industry incumbents and entrants, intra-industry boundaries should be defined in terms of the competences that are needed to serve each submarket (Abernathy \& Clark, 1985; Danneels, 2002). I distinguish between two types of competences that together determine firm success: technological and customer competences of submarkets within the same industry (Danneels, 2002, 2004; Mitchell, 1992). ${ }^{2}$ Technological competences refer to the ability to use

\footnotetext{
${ }^{1}$ While there is no objective definition of submarkets, they are often defined as specialized product clusters to which firms in the same industry can be differentiated along numerous dimensions, such as the technologies they use, the product/services they offer, or the customer segments they target (Sutton, 1998; Klepper \& Thompson, 2006).

${ }^{2}$ I choose to focus in particular on technological and customer competences because they are the two key conditions that are jointly needed to be successful in a submarket: firms should be able, first, to physically develop and manufacture products (which requires technological competences) and, second, to sell them to address different customer needs (which requires customer competences) (Mitchell, 1992; Danneels, 2002: 1102).
}

certain technologies to bring a product or service into existence, such as capabilities involved in developing and manufacturing products by using certain process technologies, whereas customer competences refer to the ability to address different customer needs with these offerings, such as capabilities involved in developing product features, developing market applications, and understanding customers' needs (Danneels, 2002, 2004; Priem, 2007).

Considering multiple independent submarkets that remain non-converging (Sutton, 1998), industry incumbents do not possess all necessary sets of competences to compete with entrants in all the submarkets of an industry (e.g., Sosa, 2009). In other words, the lack of convergence in submarkets breaks the mechanism through which industry incumbents dominate as postulated in the traditional monolithic view. However, as the competence profiles of hitherto separate submarkets evolve over time, some submarkets converge, allowing firms to leverage their competences across submarkets. I argue that while convergence in both technological and customer competences favors industry incumbents over entrants, as occurred in the U.S. tire industry (Buenstorf \& Klepper, 2010), ${ }^{3}$ a lack of convergence in either type of competence gives entrants sufficient room to gain a foothold in the industry and to potentially disrupt industry incumbents (Adner \& Zemsky, 2005; Malerba \& Orsenigo, 2002), as occurred in the computer or laser industries (Bhaskarabhatla \& Klepper, 2014; Buenstorf, 2007; Stieglitz, 2003). ${ }^{4}$ I use the term "disruption" to refer to

\footnotetext{
${ }^{3}$ Buenstorf \& Klepper (2010: 1567) find that the cord tires submarket was initially independent from the fabric tires submarket; however, over time, enhanced innovation efforts in the cord tire submarket spurred a great wave of entry and exit, making their products attractive to an increasingly broad range of customers. The cord tires submarket began to poach sales from the fabric tire submarket. However, because technological developments related to cord tires also gradually built on fabric tires, the cord tire submarket soon became tied to the fabric tires submarket. Consequently, despite opening up opportunities for entrants, cord tires did not upset the dominance of leaders in the tire industry. Incumbents' dominance was reinforced.

${ }^{4}$ This argument does not necessarily indicate that disruption will occur every time submarkets remain nonconvergent, but continued separation of submarkets is the only way in which entrants can gain a foothold, after which they may potentially disrupt incumbents. This argument is in line with that of Christensen and his coauthors: Disruptive innovation does not guarantee success; it is intended to explain an approach to competition (Christensenet al., 2004; Christensen et al., 2015).
} 
the process through which entrants gain a foothold in part of an industry by better adapting to the changing ways of producing or selling products than industry incumbents, which eventually flounder (Adner, 2002; Christensen, 2006; Christensen, Anthony, \& Roth, 2004; Christensen, Raynor, \& McDonald, 2015; King \& Baatartogtokh, 2015). Hence, industry incumbents (entrants) are characterized by less (more) flexibility in adjusting to changes in the industry structure (Leonard-Barton, 1992). As a strategic response to disruption, multiplant industry incumbents can reposition themselves by changing their firm scope and product portfolio across submarkets while not necessarily exiting the industry entirely (Sosa, 2013). Thus, the success of industry incumbents or entrants in this paper corresponds to continued plant operations in a submarket-not survival at the industry level in general (cf. Argyres et al., 2015). ${ }^{5}$ If no convergence occurs in either type of competence, the continued separation of submarkets results in the co-existence of industry incumbents and entrants, as occurred in the turboprop engine (Bonaccorsi \& Giuri, 2000) and shipbuilding (Thompson, 2005) industries.

The global semiconductor manufacturing industry is used to test the predictions of this theory. In addition to its economic and policy prominence, this industry provides significant intra-industry heterogeneity; thus, it is an ideal setting to test the theory. The industry encompasses various manufacturing technologies (such as CMOS, Bipolar, and BiCMOS) and products with different key functionalities (such as DRAM, MPU, mixed signal, and light-emitting diode (LED) chips). The findings support the predicted relationships: submarkets that converge around both a homogeneous technology profile and a homogeneous market profile are more likely to experience semiconductor manufacturing production facility (fab) exits by entrants than by industry incumbents. Entrants into submarkets with convergence only in technological competences or only in customer competences-but not in both-are

\footnotetext{
${ }^{5}$ While the majority of the industry evolution and technology innovation literature considers that between entrants and incumbents, one survivor wins while the other dies (e.g., displacement, demise, or failure of incumbents); I suggest that industry incumbents can also make strategic moves-such as repositioning within the industry by closing production facilities in certain submarkets-as a response to changes in the intra-industry structure and disruption by entrants. Significant ongoing debate on this topic justifies my approach that disruption does not necessarily constitute an existential threat (Lepore, 2014; King \& Baatartogtokh, 2015; Gans, 2016).
}

able to survive longer, providing the necessary context to create disruptions.

These results highlight the importance of using a competence-based approach to define intra-industry boundaries and of considering the interaction between technology and the market convergence of submarkets when analyzing the competitive implications of industry evolution. Regarding the first point, I conceptualize the intra-industry structure by differentiating the competences that are needed in each submarket; i.e., I draw attention to the strategic significance of competences at the submarket level and their role in determining firms' competitive positions, such as their long-term survival and repositioning. More specifically, following the influential work of Abernathy and Clark (1985), this study is-to my knowledge-the first to apply a competence perspective to the dynamics of industry evolution. Second, I consider the "convergence" dynamic to determine how the evolution of the technology and market dimensions of the intra-industry structure determines firm success. In this way, I can categorize disruptions into two types-technology disruptions and market disruptions-depending on where they originate.

\section{LITERATURE REVIEW}

A large body of literature has analyzed the relative fate of incumbents and entrants in the course of industry evolution (see Ansari \& Krop (2012) for a recent review). Here, I provide a brief synopsis of this work to identify inconsistencies, unarticulated assumptions, and gaps regarding three related questions: (1) What factors drive the convergence (or lack thereof) of the intra-industry structure? (2) How do technology- and market-related resources and competences affect the relative prospects of incumbents and entrants? (3) What are the strategic responses of industry incumbents to disruptive industry change?

\section{Convergence and Industry Evolution}

In the industry evolution literature, a number of models have been developed to investigate changing industry structures, particularly the redefinition, blurring, or even removal of intra- and inter-industry boundaries by converging technologies and markets (Greenstein \& Khanna, 1997; Lei, 2000; Stieglitz, 2003). Comparing earlier efforts with more recent ones, one can observe the progression of models based on exogenous changes (Gort \& Klepper, 1982), such as major innovations (Jovanovic \& MacDonald, 
1994) and dominant designs (Utterback \& Suarez, 1993), as well as endogenous changes, such as the scale-appropriability relationship (Klepper, 1996) or uncertainty and sunk costs (Cabral, 2012), which subsequently lead to the industry's consolidation into a stable oligopoly (through a shakeout) (Klepper, 1997). For instance, in the U.S. television, automobile, and tire industries, the convergence of previously separate submarkets-e.g., black-and-white vs. color TV, cord vs. fabric tires, and rural vs. urban automobile users-did not offer sufficient opportunities for entrants to survive, and entrants thus failed to challenge industry incumbents' dominance (Buenstorf \& Klepper, 2010: 1567). Convergence occurs in these models because of the depletion of product innovation opportunities. For example, in Klepper's scale-appropriability model (Klepper, 1996), product innovations open up new submarkets, but they are immediately imitated in the subsequent period, and new demand is added to the mainstream submarket's total demand in favor of industry incumbents, which eventually gain an insurmountable cost advantage over later entrants (Klepper, 1996: 566).

More recently, the industry evolution literature has also included customers and other stakeholders in explanations of this convergence process (Argyres et al., 2015; Benner \& Tripsas, 2012; Bhaskarabhatla \& Klepper, 2014; Suarez, Grodal, \& Gotsopoulos, 2015). For example, Argyres et al. (2015) argue that it is not the dominant design that triggers convergence of the within-industry structure, but rather the introduction of a particular pioneering new product design for which demand surges in an unexpectedly intense way, which they call an "innovation shock." Examples of this phenomenon include the Ford Model T, the RCA color TV, and the Apple Macintosh, iPod, and iPhone. Similarly, Suarez et al. (2015) propose the idea of a "dominant category"-the conceptual schema to which most stakeholders adhere when referring to products that address similar needs and that compete for the same market space. For example, in the smartphone industry, producers introduced products for which they claimed such disparate categories as "handheld PDA," "multimedia device," "business tool," "gaming device," and "handheld computer." As the industry developed further, this initial phase of categorical divergence was followed by a phase of convergence to the dominant category: the "smartphone" (Suarez et al., 2015: 439).

In all these studies, industry evolution results in convergence toward a particular technology or a homogeneous product market, in which later entrants are left with neither viable opportunities to gain a foothold nor chances for survival. In contrast, a lack of convergence in the industry's technologies or markets gives entrants viable options to avoid engaging in head-on competition with and being eliminated by industry incumbents (Windrum \& Birchenhall, 1998). For instance, in semiconductor manufacturing, technologies that are three and four generations behind the frontier continue to be purchased and used (Adner \& Snow, 2010), giving entrants additional chances to break into incumbent markets. The non-convergence of submarkets is not covered in previous industry evolution models, except in the underappreciated foundational work of Sutton (1998). While the assumption of the full appropriation of returns to innovation by industry incumbents through the convergence of technologies and product markets coherently explains "when incumbents dominate," it also restricts existing models' ability to account for a possible nonconverging submarket structure and opportunities for disruption (cf. Danneels, 2004).

\section{Technology- and Market-Related Resources and Competences}

In a parallel and closely related body of research, innovation scholars have developed concepts such as competence-destroying innovation (Tushman \& Anderson, 1986), architectural innovation (Henderson \& Clark, 1990), and disruptive innovation (Christensen \& Bower, 1996) to explain the dethronement of entrenched incumbents by entrants. Technology-related arguments are based on incremental versus radical innovations (Dewar \& Dutton, 1986; Henderson, 1993), whereas marketrelated arguments are based on sustaining versus disruptive innovations (Christensen, 1997). Incremental changes are often related to progress along a technological trajectory defined by a technological paradigm, while radical changes are associated with the emergence of a new paradigm (Dosi, 1982) that leads to intensified technological competition or even to a complete breakdown of competitive patterns (Anderson \& Tushman, 1990; Henderson \& Clark, 1990). Consequently, a process of "creative destruction" (Schumpeter, 1994) unfolds, which opens up possibilities for new entrants and eventually leads to the demise of established firms (Foster, 1986; Utterback, 1994). In contrast, sustaining and disruptive innovations focus on whether the products of different submarkets 
address the needs of existing customers or of emerging and different customers, respectively. Scholars argue that incumbent firms with sustaining technology may fail because of inefficient resource allocation between the original sustaining technology and the new disruptive technology (Christensen, 1997; Christensen \& Bower, 1996). Furthermore, an alternative market-related explanation states that industry incumbents may be better positioned to take advantage of new technologies than entrants because they own or have better access to complementary assets that are needed to commercialize the product, such as marketing, sales, and distribution (Hill \& Rothaermel, 2003; Rothaermel \& Hill, 2005; Sosa, 2011; Teece, 1986; Tripsas, 1997). The explicit assumption in all these studies is that although technologies improve over time, preferences in each customer segment remain relatively static (Sood \& Tellis, 2011; Tripsas, 2008). Thus, this research does not address the role of changing consumer needs in each submarket, particularly the firm capabilities that are needed to address these changing needs (Danneels, 2003).

While the complexity of incumbent-entrant dynamics can best be understood by concurrently analyzing technology- and market-related resources and competences over time, few studies have done so (see, Abernathy \& Clark, 1985; Clark, 1985 for exceptions). For example, Abernathy and Clark (1985) categorize innovations as being incremental or radical in terms of their transilience on the technology and market sides-the capacity of an innovation to substantially change the technical capabilities and market-customer linkages. Nevertheless, the existing literature has not focused on differentiating the (technological and customer) competences that are needed in each submarket.

\section{Responding to Disruptive Industry Change}

Along with entrants' disruptive capabilities and strategies, industry incumbents' responses also play an important role in how incumbents cope with industry change (e.g., Ferrier, Smith, \& Grimm, 1999; Jiang, Tan, \& Thursby, 2011; Ross \& Sharapov, 2015). Depending on their ability and motivation to respond, industry incumbents can consider various strategic reactions to disruption, such as adopting, ignoring, attacking, or fleeing from the disruption (Charitou \& Markides, 2003). Incumbent leaders generally have more abundant and long-invested resources than latecomers and can thus safeguard themselves against the impending loss of the entirety of the market (such as bankruptcy or exit from the industry). As Gans (2016) states, "To be sure, facing disruption is no picnic. But it also isn't the existential threat that so many see it as." Studies therefore need to consider a broader range of incumbent outcomes, not simply survival (Ansari \& Krop, 2012).

Repositioning. Repositioning-that is, abandoning a firm's current positioning and adopting a new one-has been understudied as a strategic response to disruption (Wang \& Shaver, 2014, 2016). Industry incumbents facing disruption can strategically reposition themselves by changing their focus across submarkets, e.g., retrenching the operations in a particular submarket while not necessarily exiting an industry entirely (cf. Argyres et al., 2015; de Figueiredo \& Silverman, 2007). In the laser printer industry, for example, certain manufacturers repositioned to differentiate themselves from the industry-dominant Hewlett Packard, while others repositioned to follow the leader (de Figueiredo \& Silverman, 2007). Similarly, Argyres et al. (2015) find that when the Ford Model T was introduced in the U.S. automobile industry, firms in the lowhorsepower segment repositioned to middle- and high-horsepower segments to avoid the competition created by Ford.

While the majority of the industry evolution and technology innovation literature considers that between entrants and incumbents, one survivor wins while the other dies (e.g., displacement, demise, or failure of incumbents); extant research lacks empirical focus on the repositioning of multiplant multiproduct industry incumbents. Consider Intel, which in 2015 operated 17 semiconductor manufacturing production facilities (fabs) worldwide. Claiming Intel's possible disruption at the firm level will require the bankruptcy or exit of Intel from the entirety of the industry, which is definitely less credible, testable, and viable than claiming Intel's repositioning within the same industry by closing one or more of its fabs (while continuing operations in the remaining ones and opening new ones in other submarkets).

\section{Synthesis}

In summary, established theories of industry evolution fail to show that more than one evolutionary pattern in industry structure may arise in terms of incumbent-entrant dynamics: (1) dominance of incumbents, (2) disruption by entrants, and (3) the continued separation of submarkets. The traditional 
monolithic view covers only the first outcome and explains away the rest as "irregularities" (Klepper \& Thompson, 2006: 876). While these patterns are not necessarily presented as mutually exclusive in the literature, it is arguable that one can observe either dominance of incumbents or disruption by entrants when submarkets converge. In the next section, I introduce a competence-based view of industry evolution to show that the convergence of the intraindustry structure-defined in terms of the critical complementary competences to produce and sell products of different submarkets-can account for all these outcomes.

\section{THEORETICAL DEVELOPMENT AND HYPOTHESES}

In my theoretical model, different submarkets require different competences. As the competence profiles of hitherto separate submarkets evolve over time, i.e., they converge toward each other or not, a selection process occurs between industry incumbents and entrants. To evaluate this convergence, I focus on two types of closeness between submarkets: technology closeness and market closeness. Technology (market) closeness is related to whether the technological (customer) competences required in one submarket can be leveraged across submarkets, thus affecting the degree to which industry incumbents can respond to disruption by entrants from the technology (market) side.

To provide a simple illustration of the theory, imagine the case in which only two submarkets exist in an industry, $\mathrm{S} 1$ and S2. ${ }^{6}$ There can be incumbents and entrants in both submarkets (denoted by Incumbent 1, Incumbent 2, Entrant 1, and Entrant 2, respectively), and they are characterized by their flexibility in adjusting to changes in the industry structure (Leonard-Barton, 1992). ${ }^{7}$ Thus, while industry incumbents have higher adjustment costs than entrants, they have had more time and resources to invest in building the competences

\footnotetext{
${ }^{6}$ It is important to note that my claim is not for dyadic submarket relationships in this paper. The empirical analysis allows for multiple submarkets. I pursue an industry-level homogeneity vs. heterogeneity argument, which requires consideration of all submarkets interacting with each other.

${ }^{7}$ The inertia of industry incumbents is related to both their age and size (Hannan \& Freeman, 1984; Sutton, 1997). In line with this consideration, industry incumbents are later operationalized as firms that own more than 1 fab.
}

needed to compete in the submarket (Argyres et al., 2015). Entrants do not fully possess these competences because they have not yet incurred sunk costs, such as building multiple plants using a given technology. Starting at time $t=0$, each submarket has a technology competence profile and a customer competence profile (see Figure 1, left). The $\mathrm{X}$ vector comprises the skill set and the knowledge base required in manufacturing processes within a particular submarket (Stieglitz, 2003). The $\mathrm{C}$ vector exhibits the competences required in developing product characteristics in a submarket that provide customer benefits (functionalities) (Adner \& Levinthal, 2001; Benner \& Tripsas, 2012; Danneels, 2002). The vertical (horizontal) distance between S1 and S2 denotes the technology (market) closeness (see Figure 1, right), and this distance is updated every period. The optimal competence profile to serve a submarket changes over time both exogenously, in response to technological and market changes, and endogenously. Industry incumbents' limited ability to adapt increases their incentives to apply their (submarket's) existing competences to other submarkets. They can at most invest in related-rather than unrelated-submarkets (Mitchell \& Skrzypacz, 2015). Thus, Incumbent 1 and Incumbent 2 pull the other submarket toward theirs, and this process endogenously results in convergence between $\mathrm{S} 1$ and S2. For example, in semiconductor manufacturing, driven by investments by large-scale industry incumbents, such as Intel in logic and Samsung in memory, in the late 1980s, the technological competence profiles of these two submarkets became increasingly dominated by the Complementary MetalOxide-Semiconductor (CMOS) technology (Jiang et al., 2011). Through this convergence process, previously separate logic and memory submarkets were pulled toward one another, resulting in technology convergence between these two submarkets. A similar counterforce for divergence can be argued to endogenously move submarkets away from each other by entrants' investments in unrelated areas (Mitchell \& Skrzypacz, 2015).

For simplicity, let us keep S1's position constant, and let S2 converge to S1. Hence, firms in S1 do not need to update their competences-thus, Incumbent 1 already matches the stable conditions in $\mathrm{S} 1$ better than Entrant 1-but firms in S2 do. At time $t=1$, S2's technology closeness to S1 increases, that is, S2's technological competences become increasingly similar to those of S1. This leads to a more homogeneous technological competence structure between the two submarkets. Forced to adjust their technological 
FIGURE 1

Technology and Customer Competence Profiles of Submarkets

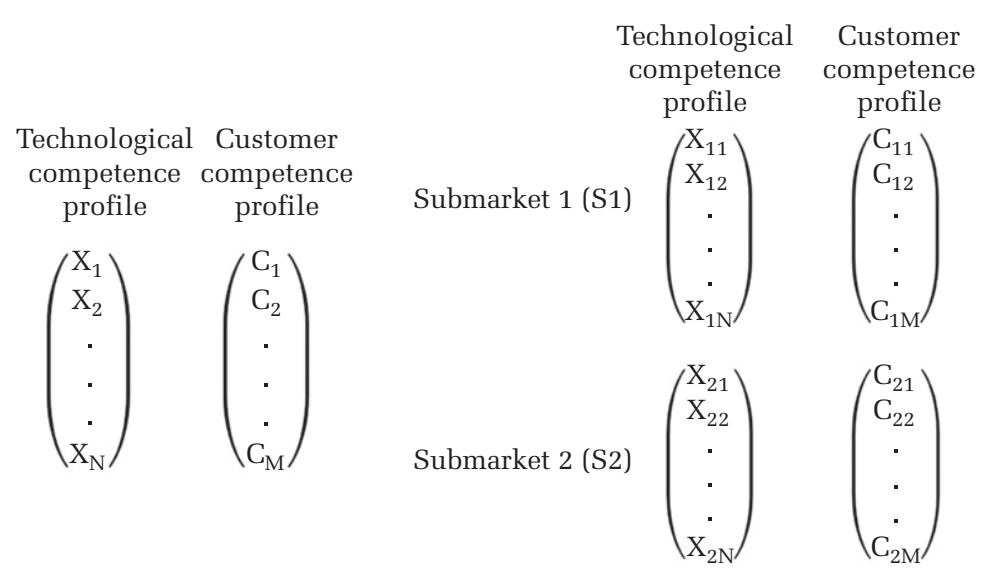

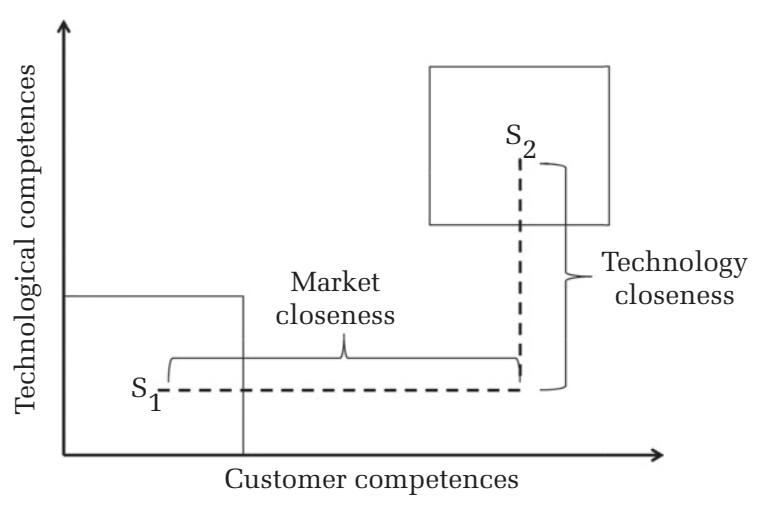

competences to those of S1, Incumbent 2 will have greater difficulty than Entrant 2 in adapting to the new optimal competence profile.

The change of S2's position in the competence space favors Entrant 2 against Incumbent 2, but they now face competition from Incumbent 1 , who can leverage its technological competences to compete in S2. The real added value of incorporating the industry submarkets model into the incumbent-entrant dynamics originates from the consideration of this additional competition. To gain a foothold and survive, Entrant 2 will require a differentiating competence profile that is unlike that of S1. Non-convergence in customer competences (i.e., unchanging market closeness) offers such a path. While S1 and S2 now use a common portfolio of technological competences to produce their products, these products are still sold to different types of customers and satisfy different needs (Figure 2, Technology convergence). Continuing our previous example, although logic and memory submarkets converged within the technology dimension, their products with distinct features continued to address different customer needs, which leaves exposed areas in the customer competence space that are not covered by Incumbent 1, giving Entrant 2 sufficient possibility to grow and gain a foothold in the industry. Similar rationale applies to the symmetrical case, where customer competences converge and technological competences remain non-convergent (Figure 2, Market convergence).

Alternatively, now imagine the case in which both types of S2's competences converge to those of S1 (Figure 2, Technology and Market convergence). This convergence denotes a more radical change in S2's competence portfolio with more uncertainty.
This time, Incumbent 2 will suffer even more from adapting its competences than Entrant 2. However, in this case, faster adaptation might result in disadvantages for Entrant 2. Organizational ecology's inertia theorem (Hannan \& Freeman, 1984) claims that under certain conditions, inertia and higher adaptation costs can be a selection advantage-for example, when environmental change is unpredictable or when reorganizations ignite long and partially unforeseen cascades of change (Péli, 2009). Péli (2009: 358) states that the novelty of the HannanFreeman argument is that there are many contexts in which survivors are chosen from organizations with inertia (Hannan \& Freeman, 1984: 155). ${ }^{8}$ Convergence in both types of competences characterizes such a condition: rapid adaptation exposes Entrant 2 to earlier and fiercer head-on competition against Incumbent 1. Because Entrant 2 will not be able to differentiate in any competence profile, it will eventually fail to gain a foothold and exit. Incumbent 2 , on the other hand, with its inert and routinized structure of operations, adapts later-but does so more effectively-than Entrant 2 because Incumbent 2 has more slack resources and capabilities, specifically more integrative and strategic renewal capabilities (Helfat \& Campo-Rembado, 2016; Kapoor, 2013), or more money, which enables it to endure the head-on competition with Incumbent 1 better than Entrant 2.

\footnotetext{
${ }^{8}$ Other scholars in management (Posen \& Levinthal, 2012; Stieglitz, Knudsen, \& Becker, 2016), economics (Keller \& Rady, 1999), and biology (Stephens, 1991) likewise argue that highly dynamic environments undermine the value of exploration and flexibility and that increased dynamism requires less exploration and more inertia.
} 
FIGURE 2

Technology and Market Convergence with Two Submarkets
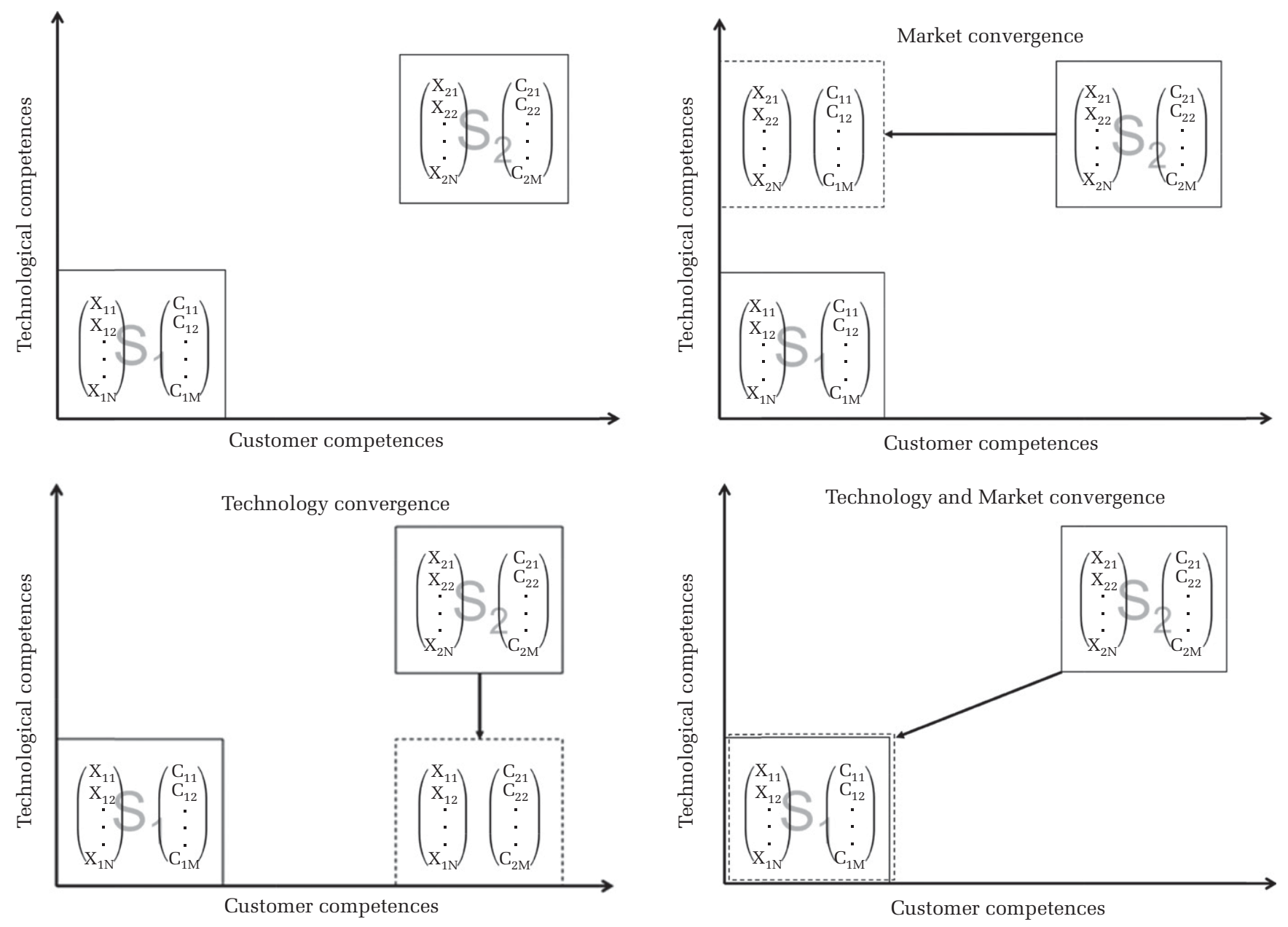

In summary, inertia and higher adaptation costs provide Incumbent 2 with a selection advantage against Entrant 2 when both types of competences converge.

The model above can be easily generalized in at least three ways. First, by allowing $\mathrm{S} 1$ to converge to S2, we can observe new competition between Entrant 1 and Entrant 2 (instead of between Incumbent 1 and Entrant 2). This competition will also depend on two new assumptions: (1) these submarkets converge to each other with the same speed and (2) they have the same size. Without these assumptions, for example, if S2 converges toward S1 faster than S1 does to S2, then Entrant 2 will face a combination of Entrant 1 and Incumbent 1 . However, in any case, the model is about the success of firms in the focal submarket; S2 in this illustration, either against Incumbent 1 (when S1 remains constant) or against

Entrant 1 (when S1 also converges). Second, we can also allow the scale of submarkets to vary in the model such that a larger scale of output in S1 makes it more difficult for Entrant 2 to outcompete Incumbent 1. The scale differences across submarkets may disadvantage entrants because large-scale submarkets provide firms with increasing returns to size and decreasing average costs (Klepper, 1996). Furthermore, large submarkets have mostly larger firms (Coad \& Guenther, 2013). Thus, such differences increase the minimum efficient scale for operating profitably, eventually engendering consolidation and incumbent dominance. Finally, we can also include multiple submarkets in the model. In such a case, the reference point for convergence changes from the center of one submarket to the center of all submarkets, i.e., the industry average (see Figure 3). 
FIGURE 3

Convergence with Multiple Submarkets where the Reference Point for Convergence Is the Center of all Submarkets, i.e., the Industry Average.

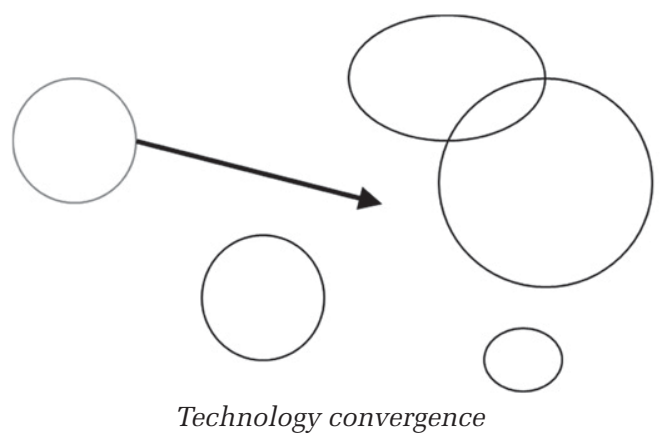

Technology convergence

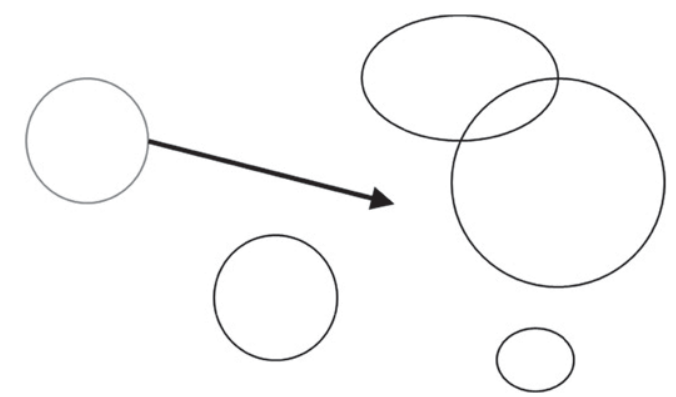

Market convergence

\section{Hypotheses}

Figure 4 shows different outcomes (i.e., dominance of incumbents, disruption by entrants, or the continued separation of submarkets) with the existence (or lack thereof) of convergence in technological and customer competences across submarkets. Since the increase in the degree of overlap is continuous rather than dichotomous, the types of convergences are indicated by arrows (cf. Danneels, 2002). In other words, the typology consists of ideal types (Doty \& Glick, 1994), but in practice, the evolution of the closeness measures is a continuous process (Christensen, Anthony, \& Roth, 2004). ${ }^{9}$

I begin with the quadrants that are asymmetric in their convergence types. The upper-right quadrant is market disruption with convergence only in technological competences. In this case, while firms increasingly use similar technologies to manufacture products of different submarkets, these products continue to provide different functionalities that address different customer needs. Because there is no increase in market closeness, entrants have a higher likelihood of surviving and breaking into incumbent markets. The cases of laser and machine tool industries are good examples of this dynamic (Bhaskarabhatla \& Klepper, 2014; Guenther, 2009; Stieglitz, 2003). In the U.S. laser industry, the development of the diode-pumped solid state (DPSS) laser by universities and government labs initiated an integrative submarket phase, which resulted in

\footnotetext{
${ }^{9}$ This approach distinguishes this paper from the majority of studies mentioned in the previous section, which base their arguments on discrete events, such as shocks or discontinuities (Anderson and Tushman, 1990; Utterback and Suarez, 1993; Suarez and Utterback, 1995; Argyres et al., 2015).
}

technology convergence across previously separate submarkets. However, while the advent of the DPSS lasers led to economies of scope in R\&D, it did not ensure that customers coalesced around a particular product design (Bhaskarabhatla \& Klepper, 2014: 1410). Products of different submarkets still offered different key functionalities (e.g., metal cutting, human eye treatment, barcode scanning, CD playing, and laser printing), requiring different customer competences. Similarly, Stieglitz (2003) and Guenther (2009) show that in the machine tool industry, the advent of (computerized) numerical controls fused the traditional submarkets of boring, milling, turning, and precision grinding. The new multi-functional automated machining devices allowed these different submarkets to rely increasingly on the same set of technological skills in their production processes. However, the industry remained characterized by an immense product variety-products with completely different key functionalities, such as firearms, sewing machines, and bicycles, required diverse customer competences. The lack of convergence in customer competences gave entrants survival advantages against industry incumbents.

Hypothesis 1 (Market disruption): Entrants will fare better than incumbents in submarkets that converge only in technological competences.

The second quadrant is technology disruption with convergence only in customer competences. In this case, products of different submarkets target segments of consumers with increasingly similar needs. As they share more product characteristics, these products are more likely to become substitutes (Geroski, 1998; Porter, 1980). In contrast, we observe a diverse set of technologies across submarkets that do not converge toward any homogeneous structure. 
FIGURE 4 Market and Technology Convergence and Incumbent-Entrant Dynamics

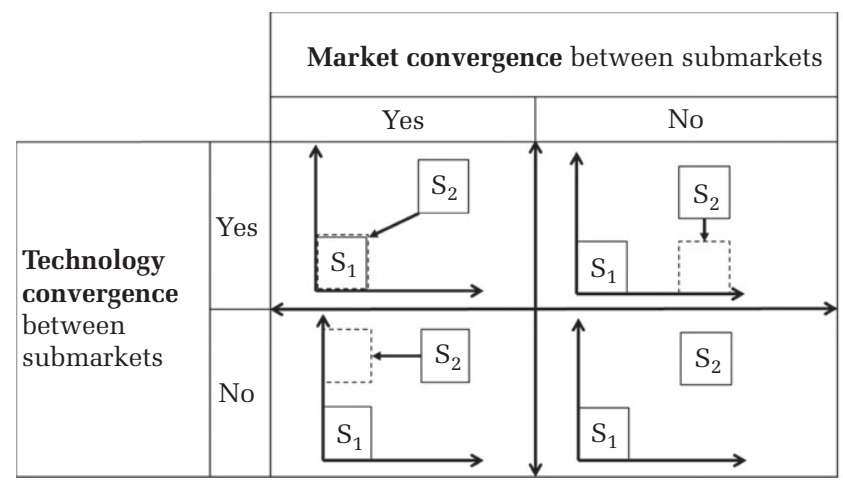

This case occurs primarily in high-technology industries in which multiple technological trajectories co-exist (Adner \& Snow, 2010; Chesbrough, 2003). In the event of disruption, industry incumbents' technological competences are likely to be destroyed by radically different technological competences, resulting in a change in industry dominance (Tushman \& Anderson, 1986). Two good examples of such market convergence (and technology disruption) are the computer and lighting industries (Bresnahan \& Greenstein, 1999; Sanderson \& Simons, 2014). In the computer industry, mainframes were sold to perform general purpose tasks, whereas minicomputers were sold to conduct highly specialized and repetitive single tasks. Accordingly, these submarkets differed substantially in terms of the customer competences needed, where product characteristics addressed the needs of customers in commercial offices versus more technically sophisticated customers in factories and laboratories. Rapid and sustained technical innovation led minicomputers to be increasingly employed for more complex and general tasks, increasing the market closeness between mainframe and minicomputer submarkets. Firms that had previously supplied different customer segments now competed for the same type of customers. However, the lack of convergence in technological competences preserved different trajectories of technological knowledge, incubating technologies that would have failed had they entered early directly against mainframe incumbents such as IBM (Bresnahan \& Greenstein, 1999: 2). In the transformation of the industry, smaller entrepreneurial firms have come to replace larger established ones. A similar example can be found in the lighting industry (Sanderson \& Simons, 2014). LED technology was first commercialized by an entrant, RCA, in 1971, using scientific principles entirely independent from

\begin{tabular}{|c|c|c|c|}
\hline & & \multicolumn{2}{|c|}{ Market convergence between submarkets } \\
\hline & & Yes & No \\
\hline \multirow{2}{*}{$\begin{array}{l}\text { Technology } \\
\text { convergence } \\
\text { between } \\
\text { submarkets }\end{array}$} & Yes & $\begin{array}{l}\text { Dominance of } \\
\text { incumbents } \\
\text { (e.g., automobilies, tires, } \\
\text { televisions) }\end{array}$ & $\begin{array}{l}\text { (Market) Disruption by } \\
\text { entrants } \\
\text { (e.g., lasers, machine } \\
\text { tools) }\end{array}$ \\
\hline & No & $\begin{array}{l}\text { (Technology) Disruption } \\
\text { by entrants } \\
\text { (e.g., computer, lighting) }\end{array}$ & $\begin{array}{l}\text { Continued separation of } \\
\text { submarkets } \\
\text { (e.g., shipbuilding, } \\
\text { turboprop engine) }\end{array}$ \\
\hline
\end{tabular}

conventional (incandescent and fluorescent) lighting sources in use. LEDs found early application in hostile outdoor environments such as traffic signals and architectural lighting because of their extended lifetime, reduced frequency of difficult bulb changes, and not burning out suddenly. Over time, process innovation led to an increase in market closeness through energy savings and quality improvements, and LED lights became attractive replacements for many buyers (Sanderson \& Simons, 2014). ${ }^{10}$ Firms required similar customer competences as those for conventional sources of lighting. However, industry incumbents' technological competences were consequently prone to becoming obsolete, especially because entrants in Taiwan, China, and Korea became prominent in LED science. LEDs have now successfully substituted existing forms of lighting, including fluorescent and incandescent.

Hypothesis 2 (Technology disruption): Entrants will fare better than incumbents in submarkets that converge only in customer competences.

The third (upper-left) quadrant represents the traditional monolithic view in which the industry life cycle (ILC) is explained well in terms of convergence toward homogeneous submarket structure and industry incumbents' dominance (Klepper, 1996). When one submarket experiences an increase in both technology and market closeness to the center of all submarkets, i.e., the industry average, the combination of technology and market convergence creates a valuable synergy (Henderson \& Cockburn, 1994)_a complementarity_that buffers industry

\footnotetext{
${ }^{10}$ Compared with incandescent bulbs, which normally last 750 to 1,000 hours, LEDs last approximately 12,500 hours and use $75 \%$ less energy.
} 
incumbents from disruption by entrants (Tripsas, 1997) and reinforces their industry dominance (Buenstorf \& Klepper, 2010). In this case, entrants have no opportunity to differentiate themselves from industry incumbents. Klepper's (1996) ILC model and Klepper and Simons' (1997) analysis of the four U.S. industries, namely, automobiles, tires, televisions, and penicillin, fall into this quadrant. For instance, during the U.S. automobile industry's advent in 1895, varying types of manufacturing methods (i.e., regarding size and types of engines (steam, electric, and internal combustion)) and varying types of consumer needs (i.e., regarding rural and urban users that valued different attributes in a car) were present. Ford's development of the Model T in 1908 ushered technology convergence around "flexible mass production" among all available manufacturing methods (Jovanovic \& MacDonald, 1994). This was followed by market convergence, as vanadium steel, a new alloy, made cars both lightweight and powerful, making them attractive to both rural and urban users. The result was the dominance of incumbents.

Hypothesis 3 (Dominance of incumbents): Incumbents will fare better than entrants in submarkets that converge in both technological and customer competences.

The last quadrant (bottom-right) is the continued separation of submarkets. In this case, we observe an evolutionary pattern in which the persistence of independent submarkets, à la Sutton (1998), involves a stable coexistence between industry incumbents and entrants. In some cases, paradoxically to the monolithic view (Klepper, 1996), submarkets do not converge and remain, as Sutton (1998: 233) calls them, "a set of isolated islands." The continued separation of submarkets has been observed in the turboprop engine (Bonaccorsi \& Giuri, 2000) and shipbuilding (Thompson, 2005) industries. Among turboprop engine manufacturers, even though high concentration resulted in an oligopolistic structure, the generalists and specialists coexisted. Because of violations of appropriability conditions and lack of scale and scope economies in R\&D, manufacturing, and marketing, it was not possible for the same manufacturer to develop several versions of the basic engine and dominate the industry by pursuing a multi-product, multi-segment coverage strategy. Thompson (2005) uses data from the U.S. iron and steel merchant shipbuilding industry, where the continued separation of submarkets occurred due to geographical conditions that prevented large vessels employed in the Great Lakes from entering western rivers. Shipbuilding firms had to choose limited locations, as they would only be able to serve those areas where their ships could be used. The use of different technologies for large and small ships also prevented the technologies from converging, leading to the continued separation of submarkets and the coexistence of industry incumbents and entrants. In line with this argument, I formulate the below hypothesis to test the lack of effect of non-convergence, i.e., the null effect (cf. Cashen \& Geiger, 2004):

Hypothesis 4 (Continued separation of submarkets): There will be a null effect on how entrants and incumbents fare in submarkets that converge in neither technological nor customer competences.

\section{EMPIRICAL CONTEXT AND DATA}

In this section, I describe the setting-the semiconductor manufacturing industry-and the quantitative data, supported by consultation from industry experts. Because of its diversity and segmented structure in terms of manufacturing technologies (such as bipolar, MOS, CMOS, BICMOS) and products with different key functionalitiesthat is, customer benefits derived from product features-(such as analog, digital, power semiconductors, signal processing, and optoelectronics), the industry provides a fruitful context with substantial variance to perform an empirical analysis. The dataset also includes capacity and investment levels, sales, entry, and exit. Three main features of the semiconductor manufacturing industry make it fit well with the theory. First, semiconductors can be easily divided into submarkets (Sutton, 1998: 358). Regarding both process technologies and key product functionalities, I can distinguish between submarkets such as analog, discrete, MEMS, ${ }^{11}$ memory, and logic chips, which can be further fragmented into an array of specialized "secondary" submarkets, such as mixed signal and linear chips for analog products; LEDs, thyristors, and transistors for discrete products; DRAMs and Flash chips for memory products; and digital signal processing (DSP) chips, microprocessors (MPUs), and microcontrollers (MCUs) for logic product families. Semiconductor

\footnotetext{
${ }^{11}$ MEMS stand for microelectromechanical systems, which are miniaturized sensors with extreme reliability, such as accelerometers and pressure sensors, which have applications in smartphones, inkjet printers, automobiles, projectors, and microphones. These include camera parts, such as movement and direction sensors for mobile phones, or accelerometers incorporated into airbags.
} 
FIGURE 5

Structure of Submarkets in the Semiconductor Manufacturing Industry

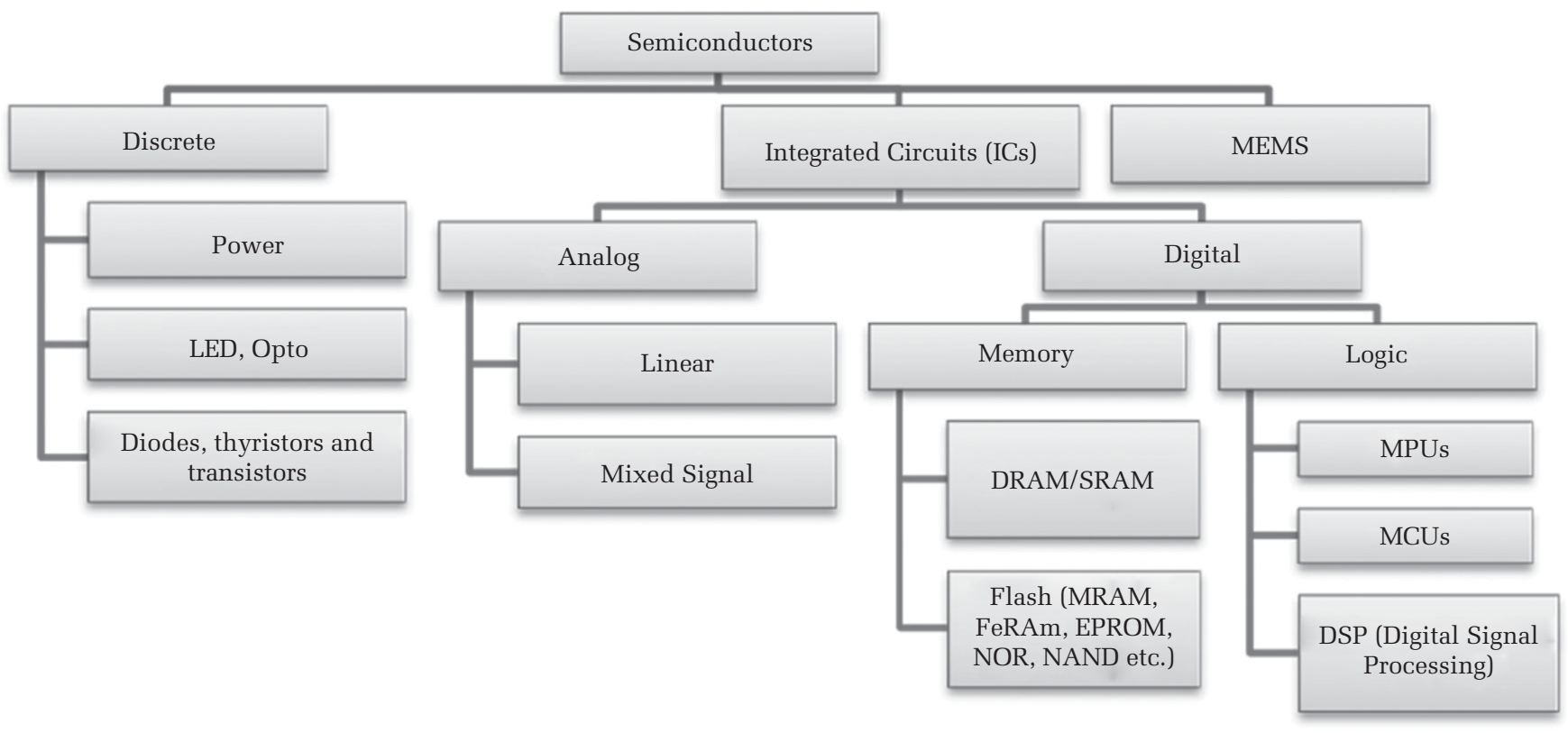

products may be viewed as a compressed group of electrical functions, where a function could be a memory bit or a logic gate (Leachman \& Leachman, 1999). An industry expert noted, "The nature of the function determines which types of applications the chip will serve, so the technologies, process steps, and manufacturing tools that are required for producing, for instance, MEMS chips and memory chips are completely different." Semiconductor submarkets also have demand-side heterogeneity that requires different customer competences. For example, data-processing devices (e.g., PCs, notebooks, and servers) typically use MPUs, DRAM, SRAM, and, more recently, NAND Flash memory chips, whereas sensors (MEMS), MCUs, DSPs, power, and analog chips can be found in modern automobiles. Another industry expert noted the following: "the design and marketing skills required for different businesses are very different. A memory company cannot become a logic company or a MEMS company overnight.” The hierarchical structure of submarkets in the industry can be seen in Figure 5.

The second feature of the industry that makes it fit well with the theory is that new product cycles emerge between semiconductor submarkets, which provides convergence toward a more homogeneous industry structure. While aggregate trends in the semiconductor manufacturing industry show signs of maturity and a shortening ILC, a closer examination of semiconductor submarkets reveals different growth patterns between submarkets. For example, recently, the DRAM memory submarket, whose products are used primarily in dataprocessing applications (such as PCs, notebooks, and servers), has stagnated and began flattening in growth, while the flash memory submarket, whose products are used primarily in mobile and embedded applications (including smartphones and tablets), has begun to take off. ${ }^{12}$ By the end of 2009, total flash memory capacity installed in fabs surpassed DRAM memory capacity, and the number of DRAM producers consolidated from 98 in 1999 to 19 by 2015. Because both submarkets require similar technologies for production (primarily CMOS) and because their different key functionalities on the market side are also converging, these submarkets might fuse in the future, forming a larger-scale hybrid submarket (DRAM\&Flash). This type of restructuring and consolidation of submarkets benefits memory incumbents, such as Samsung, as

\footnotetext{
${ }^{12}$ According to Gartner's market research, desktop PC unit sales are expected to shrink by $6 \%$, while tablet sales are expected to increase by $3.6 \%$, reaching 250 million units in 2016, cannibalizing PC sales more every day.
} 
they have already invested significantly in CMOS technology and memory chips.

Third, following Moore's law, ${ }^{13}$ incumbents in digital submarkets (recall from Figure 5 that digital submarkets are memory and logic) allocate their resources in producing chips more efficiently. This efficiency orientation does not necessarily require foresight into future markets and applications, leaving ample room for alternative technologies and innovations that are not based on mere production scaling. On the other side, analog, discrete, and MEMS submarkets do not precisely follow Moore's law. Digital chip producers increasingly face the need to integrate with the analog domain in which they interface with sensors and control elements (e.g., MEMS). This need becomes more pronounced as silicon technology, and thus Moore's law, approaches its limits. Therefore, industry incumbents that are dominant in digital submarkets are prone to possible disruption from non-digital submarkets. For example, the industry began to be affected by a new trend called "More-than-Moore," in which value is created not only by scaling production but also by incorporating different functionalities that are non-digital, such as analog, sensing, and energy harvesting, which do not necessarily follow Moore's law. Two examples of these products are system-on-a-chip (SoC) and systemin-package (SiP). Therefore, the evolutionary dynamics of semiconductor submarkets offer opportunities for disruption by entrants.

\section{Data}

The core source of data is the Semiconductor Equipment and Materials International (SEMI ${ }^{\mathrm{TM}}$ )'s World Fab Watch (WFW) dataset for the 1995-2015 period. These panel data of more than 1,000 fabs per year worldwide consist of numerous variables, such as product class (e.g., Analog, Discrete, Logic, MEMS, and Memory), technologies, products, geometries, wafer sizes, ${ }^{14}$ fab capacities, equipment,

\footnotetext{
${ }^{13}$ Moore's law states that the number of transistors on ICs doubles approximately every two years.

${ }^{14}$ Wafers are disc-shaped silicon substrates on which a number of integrated circuits (ICs) can be processed, tested, and cut into individual dies. They can have diameter sizes of $76.2 \mathrm{~mm}\left(3^{\prime \prime}\right), 100 \mathrm{~mm}\left(4^{\prime \prime}\right), 125 \mathrm{~mm}\left(5^{\prime \prime}\right)$, $150 \mathrm{~mm}$ (6"), $200 \mathrm{~mm}$ ( $\left.8^{\prime \prime}\right), 300 \mathrm{~mm}\left(12^{\prime \prime}\right)$, and $450 \mathrm{~mm}$ (18"). Larger wafer diameters come with costly equipment and machinery for fabs, but they also allow firms to produce more chips per wafer, i.e., higher economies of scale are obtained.
}

and construction costs. The initial data included 23,286 fab-year observations. While SEMI ${ }^{\mathrm{TM}}$ tracks important supply-side information used in semiconductor manufacturing, for other demand-side data, such as sales in each submarket, I utilize the VLSI Research and Yole Développement ${ }^{\mathrm{TM}}$ data on worldwide semiconductor sales per submarketyear.

Because reliably following all the product categories within a fab over time is practically impossible, SEMI ${ }^{\mathrm{TM}}$ focuses on the two major product types of each fab (such as Discrete/LED or Logic/MPU). The product class variable initially composed of a maximum of 37 different types of product classes (see Table 1). From these product classes, I allocated foundries to their corresponding submarkets because the distinguishing feature of a foundry compared to a fab of an integrated firm such as Intel is its business model-contract manufacturing-rather than the technologies or markets it focuses on. Foundries are contract-based manufacturers, such as the Taiwan Semiconductor Manufacturing Company (TSMC), which focus solely on manufacturing. For example, as made-to-order chip producers, foundries might produce memory chips or logic chips; therefore, I allocated them to these submarkets accordingly.

Following my conversations with the industry experts, I decided to exclude EPI, R\&D, and Pilot fabs from the analysis. EPI is not a submarket but rather a specialized material—a nearly perfect crystalline thin layer on wafers-that is required for some devices. EPI fabs therefore do not produce devices but instead deposit this layer for their customers, i.e., device makers, and send the wafer to them to fabricate the device. I also excluded R\&D fabs and pilot fabs, as these fabs do not necessarily belong to a certain submarket; they are for early development and production, and their capacity impact is not substantial. Accordingly, I removed 389 EPI, 790 pilot, 1,999 R\&D, and 504 R\&D-Pilot fab-year observations. Finally, I excluded future fabs (1,798 fabyear observations), as the WFW dataset includes fabs that are rumored, announced, or under construction but that are not yet in production. In total, the data include five submarkets, namely, analog, discrete, MEMS, logic, and memory, and 17,806 fab-year observations for the analysis (see Table 1).

\section{Descriptive Statistics and Patterns in the Data}

In this section, I first provide detailed descriptive evidence before I present the results of the 
TABLE 1

Submarkets in the Semiconductor Manufacturing Industry

\begin{tabular}{|c|c|c|c|c|}
\hline \multicolumn{2}{|c|}{ Initial product categories } & \multicolumn{2}{|c|}{ After organizing } & \multirow{2}{*}{$\begin{array}{c}\text { Submarkets } \\
\text { Analog }\end{array}$} \\
\hline Analog/Linear & Logic/Flash & Analog/Linear & Logic/System LSI & \\
\hline Analog/Mixed Signal & Logic/MCU & Analog/Mixed Signal & Memory/DRAM & Discrete \\
\hline Analog/Other & Logic/MPU & Analog/Other & Memory/DRAM\&Flash & Logic \\
\hline Discrete/Diode & Logic/MPU\&Flash & Discrete/Diode & Memory/Flash & MEMS \\
\hline Discrete/LED & Logic/Opto & Discrete/LED & Memory/MRAM & Memory \\
\hline Discrete/Opto & Logic/Other & Discrete/Opto & Memory/Other & \\
\hline Discrete/Other & Logic/Power & Discrete/Other & Memory/SRAM & \\
\hline Discrete/Power & Logic/System LSI & Discrete/Power & MEMS & \\
\hline Discrete/Rectifier & Memory/DRAM & Discrete/Rectifier & & \\
\hline Discrete/Thyristor & Memory/DRAM\&Flash & Discrete/Thyristor & & \\
\hline EPI & Memory/Flash & Logic/DSP & & \\
\hline Foundry/Dedicated & Memory/MRAM & Logic/Embedded & & \\
\hline Foundry/DRAM & Memory/Other & Logic/Flash & & \\
\hline Foundry/IDM & Memory/SRAM & Logic/MCU & & \\
\hline Foundry/MEMS & MEMS & Logic/MPU & & \\
\hline Foundry/R\&D & Pilot & Logic/MPU\&Flash & & \\
\hline Foundry/System LSI & $\mathrm{R} \& \mathrm{D}$ & Logic/Opto & & \\
\hline Logic/DSP & R\&D-Pilot & Logic/Other & & \\
\hline Logic/Embedded & & Logic/Power & & \\
\hline
\end{tabular}

regression analyses. The technologies that are used in semiconductor manufacturing have become specialized over time, serving different purposes in terms of each submarket's diverse products. For example, as mentioned above, CMOS has been the dominant technology in digital submarkets, i.e., memory and logic (Jiang et al., 2011), as the products in these submarkets require very low power consumption and very high integration. However, CMOS is not the only dominant technology in all semiconductor submarkets. ${ }^{15}$ In Figure 6, I present the percentages of different key technologies that are used in the analog, discrete, logic, and memory submarkets for each year. ${ }^{16}$ As the figure shows, CMOS is the predominant technology used in the memory and logic submarkets (although its predominance is decreasing because of the increasing variety of specialized technologies), whereas CMOS is not the dominant technology in the analog and discrete submarkets. Instead, bipolar

\footnotetext{
${ }^{15}$ In contrast, Jiang et al. (2011) claim that CMOS replaced bipolar technology and that it became the dominant design in the entire semiconductor industry. This assumption does not hold when we examine the nondigital semiconductor submarkets, such as analog or discrete, where bipolar technology is more often used than CMOS (see Figure 6).

${ }^{16}$ MEMS is excluded from Figures 6 and 7 for ease of presentation.
}

technology is more commonly used in these submarkets because of its advantages in high-speed operation (e.g., communication systems) and highcurrent drive capability for power applications (e.g., automotive). ${ }^{17}$

Similarly, Figure 7 shows the evolution of the product side of semiconductors, i.e., their different key functionalities. For example, while DRAM, Flash, and SRAM products dominate the majority of the production in the memory submarket, in the logic submarket, MCU, ASIC, and MPU products are observed. Both submarkets also use made-to-order chip production (i.e., foundry business), which requires similar customer competences, such as the ability to conduct contract manufacturing, demonstrating some overlap among these two submarkets on the market side. In contrast, the analog and discrete submarkets have different product portfolios: while mixed signal or linear products dominate the

\footnotetext{
${ }^{17}$ BiCMOS is another (hybrid) technology that was developed to integrate the advantages of bipolar and CMOS processes. Logic and analog submarkets require this technology more than other submarkets because their products perform the intelligent control functions of actuators, such as DC motors in the automotive industry. Furthermore, some chips are manufactured with different material technologies because their electronic properties are superior to those of silicon (e.g., SiGe, GaAs, polymers, carbon nanotubes).
} 
FIGURE 6

Technology Profiles of Analog, Discrete, Logic, and Memory Submarkets
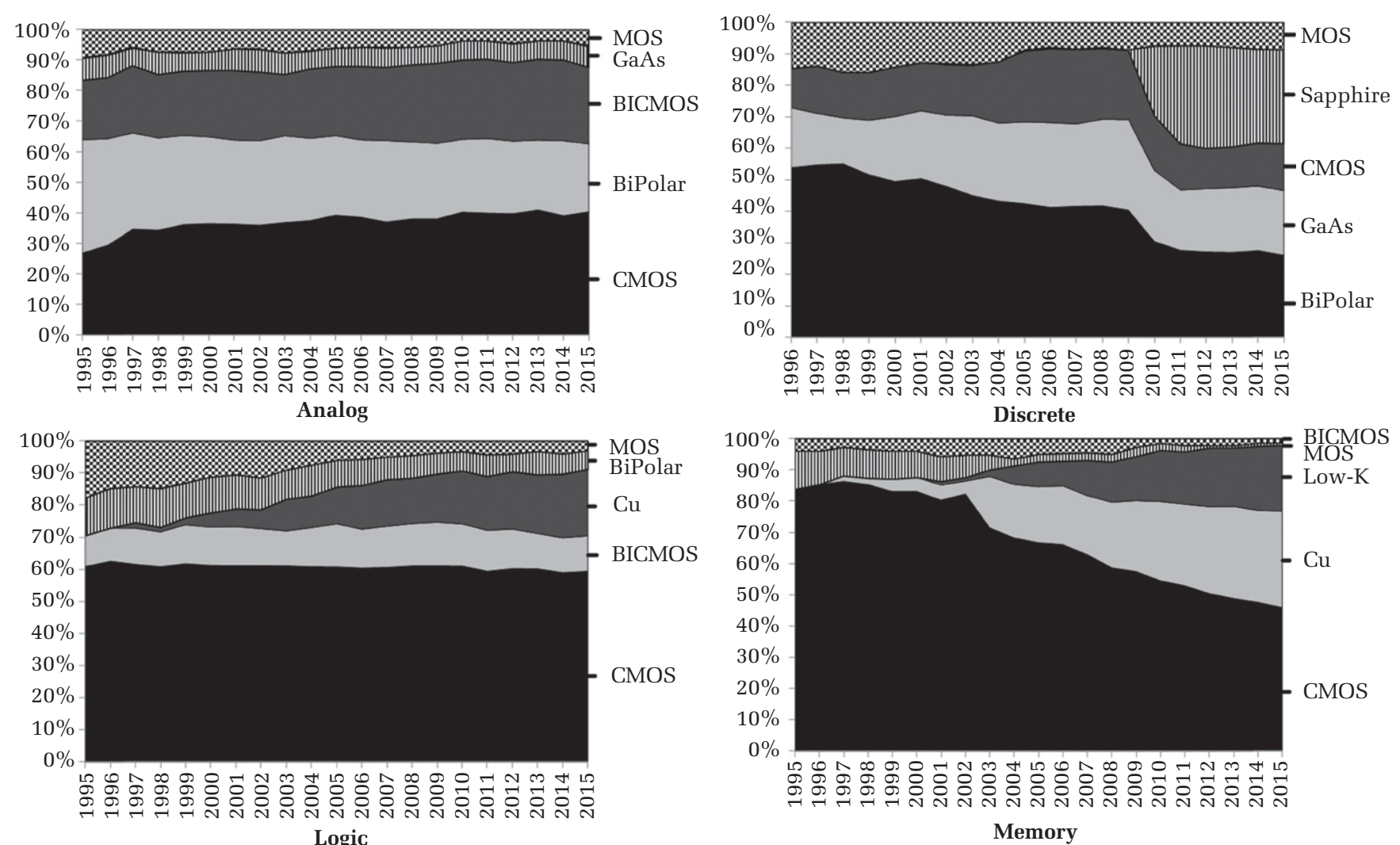

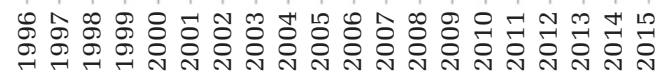

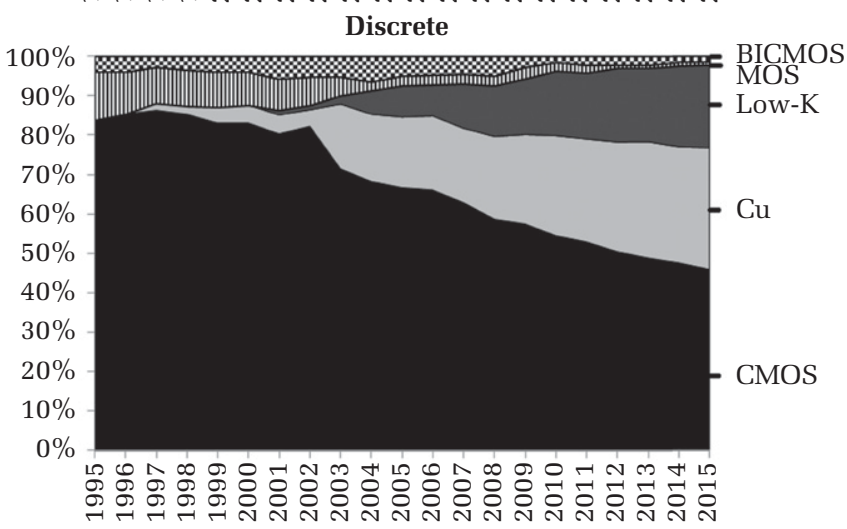

Memory

analog submarket, the discrete submarket's primary products are diodes, LEDs, optoelectronics, and transistors. This diversity decreases the market closeness between the submarkets. Different product characteristics provide customer benefits (functionalities), which in turn satisfy different kinds of customers (in different chip applications). The customer competences required to offer customer benefits derived from product features are different (Adner \& Levinthal, 2001; Benner \& Tripsas, 2012; Danneels, 2002), providing sufficient variance to test the hypotheses.

The existence of different submarkets that separate diverse technologies and key functionalities of products prevents the industry from consolidating à la Klepper and from forcing less efficient firms to exit the industry. Inside the low-efficiency submarkets, such as discrete, analog, and MEMS, firms almost never need to reach the cutting-edge wafer sizes (300 $\mathrm{mm}$ or $450 \mathrm{~mm}$ ) or geometries (sub 0.2 micron) in their fabs. Thus, submarkets buffer less efficient manufacturers against the homogenization (or convergence) of the industry's technologies and markets. For example, while a 300-mm fab of Intel can

cause another 200-mm logic fab to shut down because the logic fab is less cost efficient in the same submarket (logic), it will have a lower or no impact on a $150-\mathrm{mm}$ discrete fab, even if the discrete fab is less cost efficient. For this reason, there are practically no new entrants in the memory and logic submarkets, whereas the discrete and MEMS submarkets have recently attracted many entrants because of their ease of entry and future demand expectations. This pattern is shown in Table 2.

Entrants into the memory and logic submarkets have almost no chance of survival because they face large-scale industry incumbents, such as Intel and Samsung. Entrants can thus succeed and gain a foothold in only discrete, MEMS, and analog submarkets. As discussed previously, the existence of submarkets breaks the mechanism that the traditional monolithic view suggests leads to incumbents' dominance. The breakdown of this mechanism can also be seen in the patterns of consolidation for different submarkets. Overall, in the memory and logic submarkets, we observe exactly what Klepper (1996) theorizes: cost-efficient incumbents reinforce their 
FIGURE 7

Market (Product) Profiles of Analog, Discrete, Logic, and Memory Submarkets
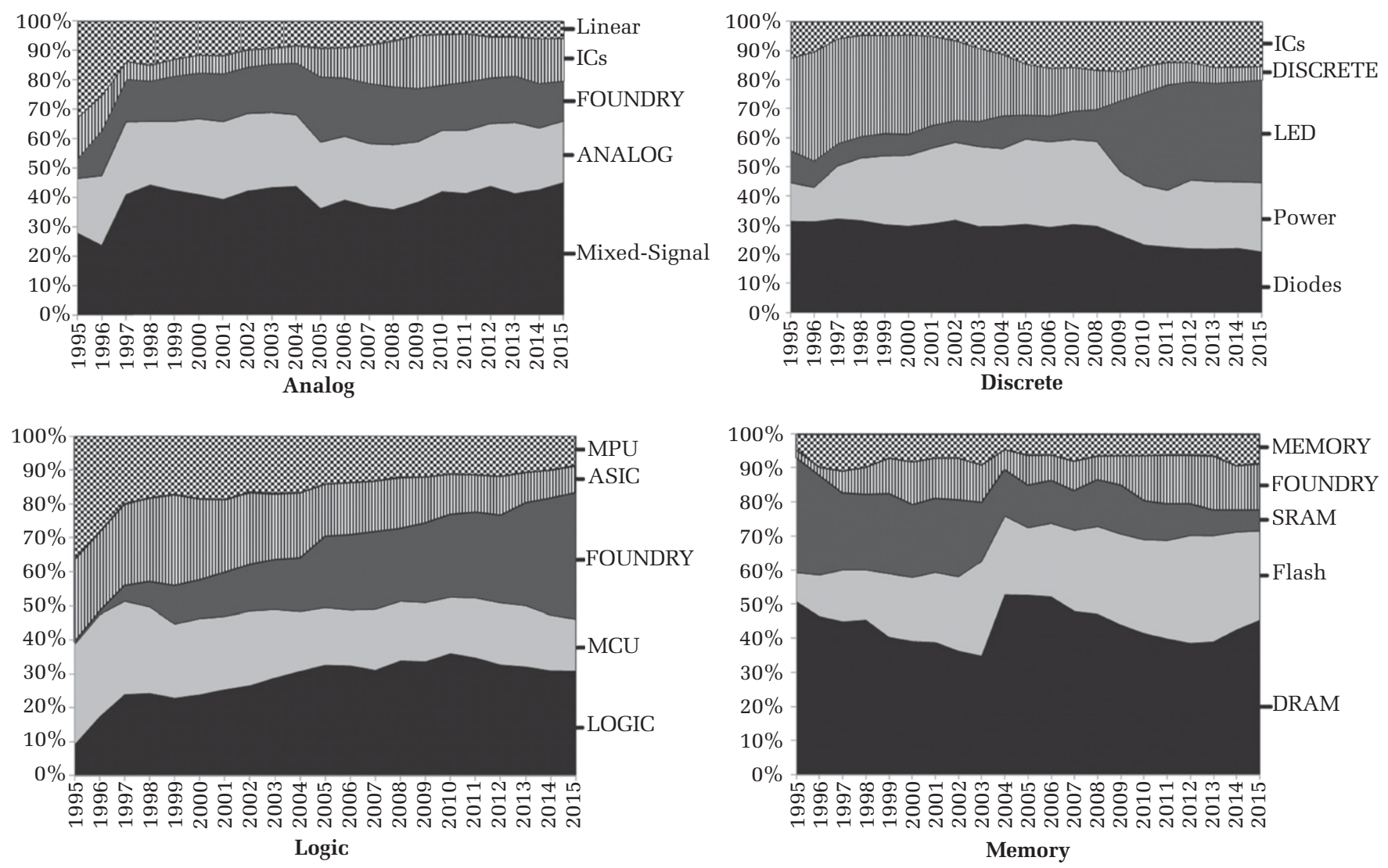

dominance by focusing on process innovation. Through wafer size enlargement, geometry shrinkage, and capacity installations, incumbents grow in size, causing new entries to decrease and to eventually stop. This process can be observed in Figure 8.

In contrast, in submarkets where "scaling manufacturing" and "commoditizing the product" do not work, such as in the analog, MEMS, and discrete submarkets, completely different patterns of evolution can be observed (see Figure 9). Compared with digital submarkets, smaller wafer sizes and greater geometries pull down the minimum efficient scale and lower the investments that are needed to operate a fab. Although these submarkets' outputs increase over time, so do the numbers of firms; thus, consolidation does not occur. These indications point to less favorable conditions for industry incumbents' dominance.

\section{METHODS}

The empirical model measures the impact of the change in submarkets' technology and market

closeness on entrant and incumbent chip manufacturers' success (likelihood to exit or reposition through fab closure) over time. Exit $t_{i j t}$ is a multilevel categorical variable that is equal to one if firm $l$ stops operating fab $i$ in submarket $j$ at time $t$ and zero otherwise. Fabs drop out of the WFW dataset only when they are no longer in operation, i.e., they are shut down by the company. Thus, even when fabs are acquired, sold, spun off, or renamed, they still exist in the dataset and can be tracked with the same assigned record identifier. For example, in the 1990s, Motorola had over 40 fabs; however, it sold off its semiconductor division into two separate companies: Freescale and ON Semiconductor. In 2015, NXP acquired Freescale. These changes do not affect the record identifier that remains with that fab until it is no longer in production.

There are many reasons why fabs close or are sold, such as market growth, turbulence, concentration, fab age, etc. However, fab closure is a good measure of performance in semiconductor manufacturing. For example, the German DRAM chip producer, 


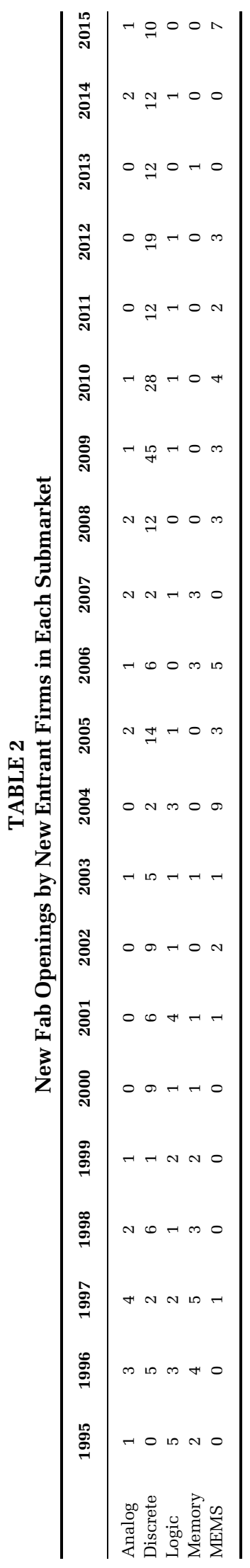


FIGURE 8

\section{Evolution in Memory and Logic Submarkets (Consolidation)}

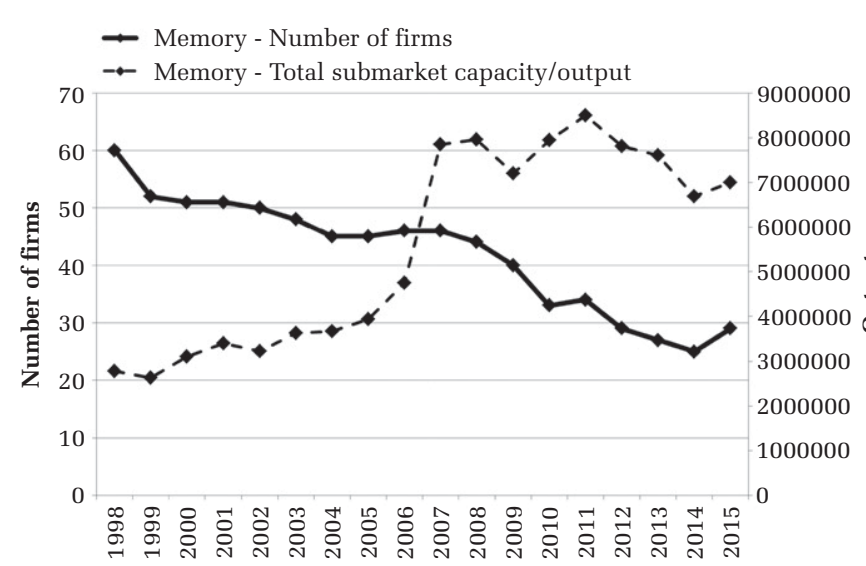

Qimonda, was the first company to close a $300 \mathrm{~mm}$ wafer fab after it went bankrupt in early 2009 because of the economic crisis. ProMOS and Powerchip followed Qimonda by closing their respective $300 \mathrm{~mm}$ wafer fabs in 2013 because of the failure to find sales for their chips and to remain in business against competition from Samsung and Hynix.

To separate different effects of independent variables on industry incumbents and entrants, I constructed an incumbent dummy measure. Industry incumbents are operationalized-in line with their higher inertia compared to entrants-as firms that own more than one fab in the industry (Dunne, Roberts, \& Samuelson, 1988). The rationale behind this coding is straightforward: firms with one fab are more flexible to changes than firms with two or more fabs. I also discussed with industry experts the correctness of this operationalization. New firm entry with multiple plants is not common in semiconductor manufacturing due to the high costs of opening a new fab; the cost of new wafer fabs and manufacturing equipment reaching $\$ 3$ billion on average (Uzunca \& Cassiman, 2017). Thus, when a new firm enters the industry, it typically enters with a single fab. Furthermore, moving from one to multiple product lines is considered a large milestone for diversifying a company's portfolio. Even TSMC, the world's largest dedicated independent foundry, first entered the industry in 1987 with one fab. The second fab was opened three years later, in 1990.

Following the prior literature (Boeker, 1989; Eisenhardt \& Schoonhoven, 1990; Giustiziero \& Wu, 2016; Li \& Atuahene-Gima, 2001; McCann, 1991), I also coded single-plant firms that had been active

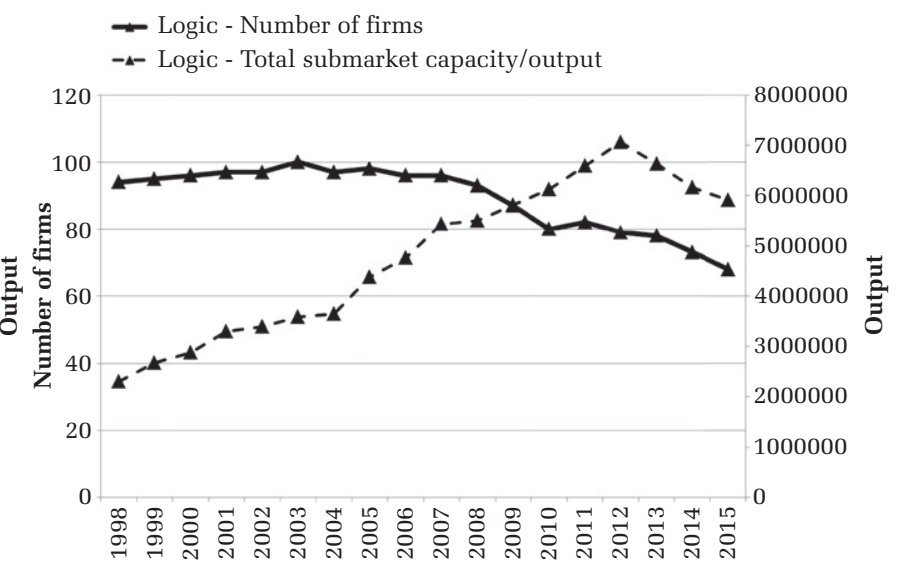

in the industry for more than eight years as incumbents. ${ }^{18}$ Therefore, for each firm, I coded Incumbent $=1$ if either the firm had at least one fab for more than eight years or had two or more fabs. In this way, I ensured that the inertia of industry incumbents was related to both their size and age (Hannan \& Freeman, 1984; Sutton, 1997) (i.e., the number of facilities a firm has increases with firm age and size). Likewise, this coding allowed me to categorize firms as industry incumbents or not, regardless of what their fabs produced. (Put differently, a firm cannot be an incumbent in one submarket and an entrant in another submarket.) On the other side, if an entrant had been acquired by an industry incumbent-the entrant had sold its fab and exited the industry-the entrant's fab was recoded thereafter as an incumbent. Likewise, if entrants had entered by buying production facilities from an incumbent-instead of by building new plants-the fab was recoded thereafter as an entrant. In this way, entrant firms account for $23.14 \%$ of the total number of firms in each year but only $5.54 \%$ of the output of production. Industry incumbents, on average, own 2.98 plants.

\section{Measurement of Technology and Market Convergence}

Imeasured the main covariates, technologycloseness $j$ t and marketcloseness ${ }_{j t}$, as the average closeness between submarket $j$ and all submarkets in the industry at time $t$. The basis of this measure is the submarketlevel analog to the uncentered correlation approach

\footnotetext{
${ }^{18}$ The results are robust to the use of alternative specifications, such as 3, 5, and 11 years.
} 
FIGURE 9 Evolution in Analog, Discrete, and MEMS Submarkets (Non-Consolidation)

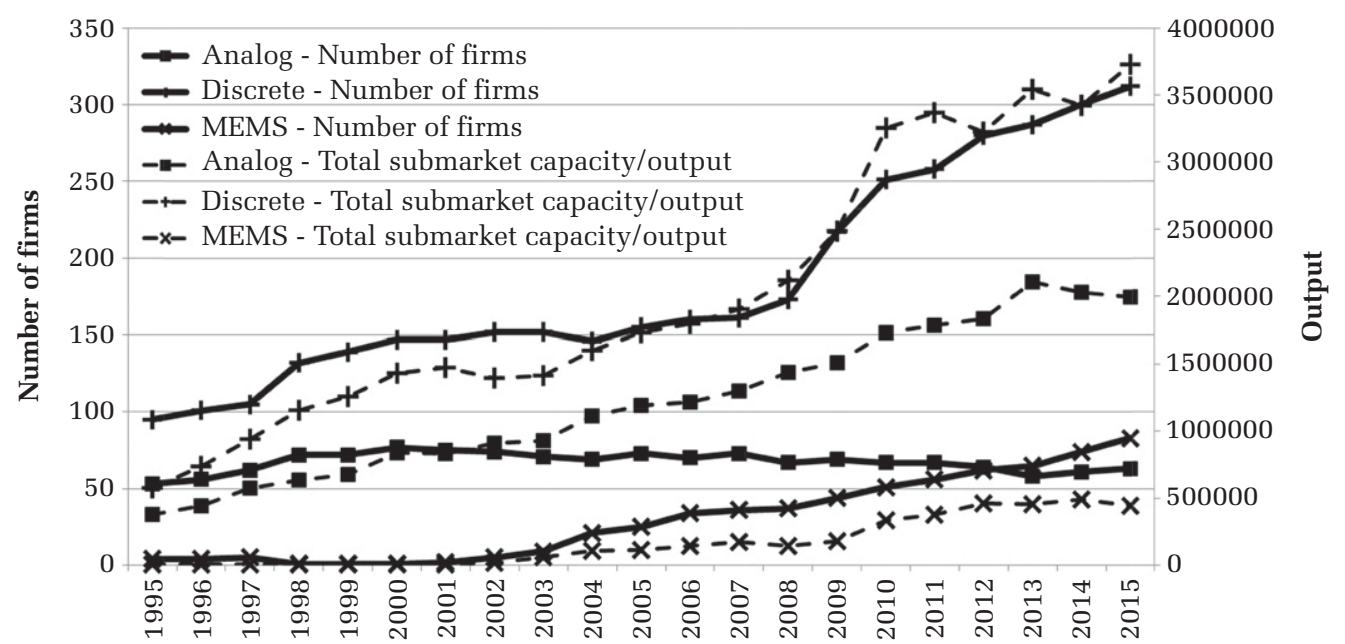

suggested by Jaffe (1986), a measure commonly used to capture the technology distance between firms. I applied this measure at the submarket level by utilizing data on the technologies used and the products produced by fabs in a given year. ${ }^{19}$ These data were not readily quantified, as they are recorded as, and embedded in, separate words in the dataset (e.g., CMOS, BiCMOS, and MOS). I decomposed this information into single words, cleaned them, and counted the most frequently appearing technologies (and products) for each submarket-year. This content-analysis approach is commonly used in text mining and is standard in data that are analyzed by counting words (Barroso, Giarratana, Reis, \& Sorenson, 2016; Ferrier et al., 1999).

This process provided an n-dimensional technology vector, $X_{j t}$, and an m-dimensional market profile vector, $C_{j t}$, whose elements are the counts of submarket $j$ 's most used technologies and products at time $t$, respectively, denoting the underlying technological knowledge bases and product characteristics. This approach is in line with Henderson and Cockburn (1994), who use, in a similar vein, publications and patents in a particular scientific area as proxies for

\footnotetext{
${ }^{19}$ There are many approaches to constructing distance measures in multi-dimensional technology and product spaces (Bloom, Schankerman, \& Reenen, 2013). I chose the method first used by Jaffe (1986) because of its ubiquity and approved validity in the literature. The Jaffe measure is obtained by constructing a weighting matrix between the location vectors of different firms. I build on this idea but seek to apply it by aggregating line of business data for multi-technology and multi-product firms to construct an analogous distance measure at the submarket level.
}

competences. The previously reported patterns in Figures 6 and 7 show the evolution of these vectors. I calculated yearly technology and market closeness between submarket $j$ and $k$ as follows:

$$
\begin{aligned}
\text { tech }_{j k t} & =\frac{X_{j t} X_{k t}^{\prime}}{\sqrt{\left(X_{j t} X_{j t}^{\prime}\right)\left(X_{k t} X_{k t}^{\prime}\right)}} \\
\text { market }_{j k t} & =\frac{C_{j t} C_{k t}^{\prime}}{\sqrt{\left(C_{j t} C_{j t}^{\prime}\right)\left(C_{k t} C_{k t}^{\prime}\right)}}
\end{aligned}
$$

This calculation yields a correlation between 0 and 1 . For example, if submarket $j$ 's technology profile perfectly coincides with submarket $k$ in year $t$, then tech $h_{j k t}$ takes the value of 1 . If the profiles do not coincide at all, i.e., if they are orthogonal, then the closeness measure takes the value of 0 . Repeating this calculation for each submarket pair produces a $5 \times 5$ technology closeness matrix and a $5 \times 5$ market closeness matrix for each year (with diagonal values being 1). Subsequently, I calculated the average closeness to all submarkets from these matrices:

$$
\begin{aligned}
\text { technologycloseness }_{j t} & =\frac{\sum_{k=1}^{5} \text { tech }_{j k t}}{5} \\
\text { marketcloseness }_{j t} & =\frac{\sum_{k=1}^{5} \text { market }_{j k t}}{5}
\end{aligned}
$$

In so doing, I obtained one single technology (and one single market) closeness measure for submarket $j$ in year $t$, denoting how close a submarket is to the industry average with regard to the technologies that they use or the key functionalities of products that 
FIGURE 10

\section{Evolution of Technology (Left) and Market Closeness (Right) of Submarkets}

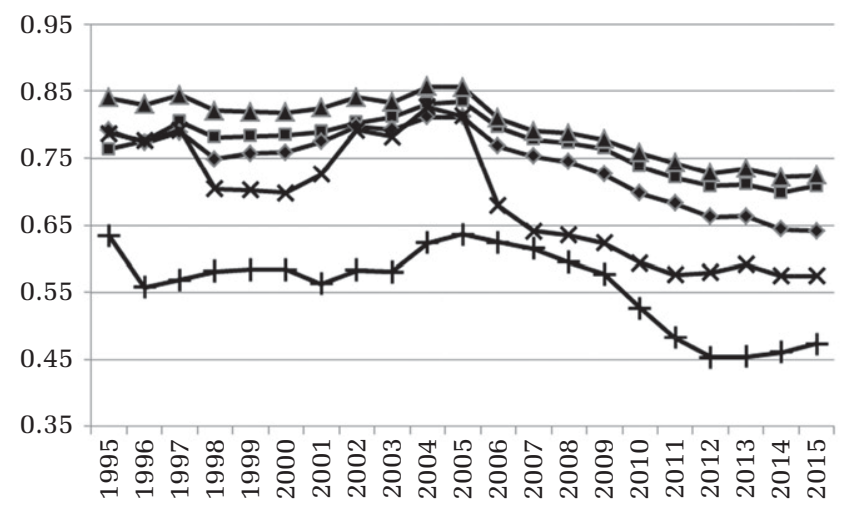

they produce. The evolution of the technology and market closeness measures are given in Figure 10. Overall, the technology closeness between submarkets has a downward pattern, in line with the general notion that the technologies that are used in semiconductor manufacturing have become specialized over time (Kapoor, 2013). On the other side, submarkets move closer with respect to the market closeness. This upward trend is also in line with "More-than-Moore," which compels firms to integrate different product characteristics and functionalities in semiconductors. The degrees of closeness also match the different patterns of consolidation observed in Figures 8 and 9. The submarkets with the maximum closeness to the others in both types of competences, such as the logic submarket, experience dominance by incumbents. The MEMS and discrete submarkets, being less close both in technology and in market closeness, better fit the case in which entrants have higher chances of success.

Given the focus on the convergence between submarkets and the dynamic nature of the closeness measures, I included them in the analyses to exploit their variations over time: increasing closeness means convergence.

\section{Control Variables and Model Specification}

In all models, I included several control variables that might have affected fab closure to ensure that they did not drive the results. These variables are defined in Table 3. I also included submarket and country fixed effects to account for any unobserved permanent heterogeneity that might have biased my results.

An event-history analysis technique, where a Cox proportional hazards model (Allison, 1984) accounts for the occurrence or nonoccurrence of an event-here,

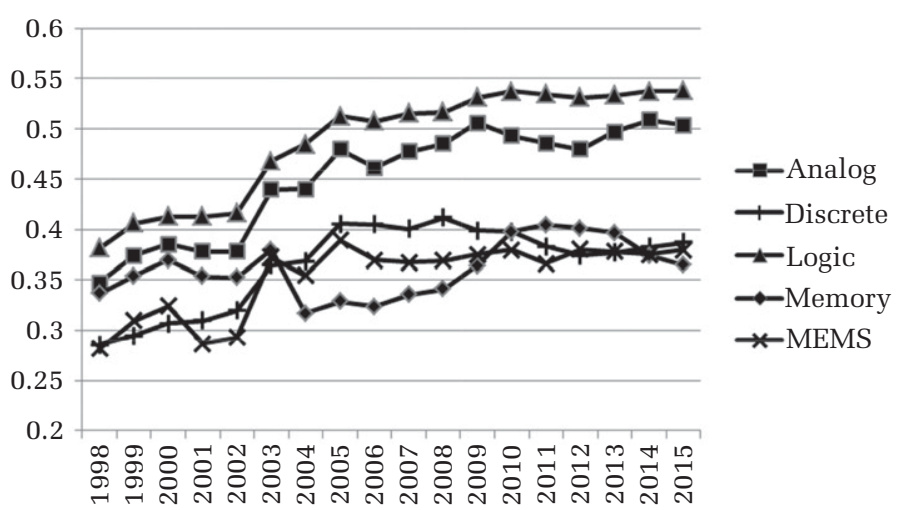

a firm's closure of its fab per unit of time, is the model specification used. I used this model to relate the set of predictor variables to the logarithmic hazard rate of fab exits per year. The Cox model was used for several reasons. First, compared with other event history techniques, it produces high-quality estimates in largesample studies such as this one, even when the great majority of observations are censored (Tuma \& Hannan, 1984). Although the data are both left- and right-censored, the Cox model makes use of the partial information in every case, as they were at risk during each year of the observation window (Allison, 1984). Second, the Cox proportional hazard model is generally used for semiparametric survival analysis, which is based on separate logit regressions for each of the sample units, but these separate regressions are presented in an aggregated format. In other words, when continuous (rather than the categorical) variables are used on the right side of the model, the Cox model is the preferred option. Third, the Cox model does not stipulate any specific form of the baseline hazard function (Morita, Lee, \& Mowday, 1993). ${ }^{20}$ Finally, the Cox

\footnotetext{
${ }^{20}$ Parametric survival analysis requires a specification of the baseline hazard model, such as exponential or Weibull specifications. For example, my inspection of the distribution of the Exit $_{\text {lijt }}$ variable showed that exponential distribution seems to fit well. However, I observed that the Weibull distribution is more valid because the departure from exponential distribution is relevant for two reasons: (1) the log likelihood is significantly improved, and (2) the $\log \mathrm{p}$, which tests whether $p=1$ significantly rejects that $p=1$ (the Weibull distribution, $h_{0}(t)=p t^{p^{-1}}$, yields an exponential distribution when $p=1$ ). Although the results are robust with respect to parametric models, I use the Cox model because of its elegance and computational feasibility (Cleves, Gutierrez, Gould, \& Marchenko, 2004).
} 
TABLE 3

Definition of Independent Variables and Summary of Predictions

\begin{tabular}{|c|c|c|}
\hline Variable & Definition & Prediction* \\
\hline TechnologyConvergence $_{j t}$ & $\begin{array}{l}\text { Year-over-year increase in submarket } j \text { 's technology closeness at } \\
\text { time } t\end{array}$ & $\begin{array}{l}\text { H1-entrant: } \\
\text { Negative }\end{array}$ \\
\hline MarketConvergence $_{j t}$ & Year-over-year increase in submarket $j$ 's market closeness at time $t$ & $\begin{array}{l}\text { H2-entrant: } \\
\text { Negative }\end{array}$ \\
\hline IndustryTurbulence $_{t}$ & The sum of gross entry and gross exit rates in the industry at time $t$ & \\
\hline SubmarketConcentration $_{j t}$ & $\begin{array}{l}\text { The Herfindahl Index: the sum of the squared market shares of all } \\
\text { firms in submarket } j \text { at time } t \text { (based on firm output) }\end{array}$ & \\
\hline \multicolumn{3}{|l|}{ Firm-level variables } \\
\hline Incumbent $_{l t}$ & $\begin{array}{l}\text { One if firm } l \text { has more than one fab at time } t \text {, and zero otherwise. One, } \\
\text { if firm } l \text { has one fab and is older than } 8 \text { years at time } t \text {, and zero } \\
\text { otherwise. }\end{array}$ & \\
\hline FabAge $_{i t}$ & $\begin{array}{l}\text { Age of fab } i \text { at time } t \text {, set equal to } t-\text { year that the fab started } \\
\text { production }\end{array}$ & \\
\hline FabUpgrade $_{i t}$ & One if fab $i$ upgrades at time $t$, zero otherwise & \\
\hline Merger $_{i t}$ & $\begin{array}{l}\text { One if fab } i \text { is operating as part of a merger at time } t \text {, and zero } \\
\text { otherwise }\end{array}$ & \\
\hline JointVenture $_{i t}$ & $\begin{array}{l}\text { One if fab } i \text { is operating as part of a joint venture at time } t \text {, and zero } \\
\text { otherwise }\end{array}$ & \\
\hline Spinoff ${ }_{i t}$ & $\begin{array}{l}\text { One if fab } i \text { has been spun-off from an existing firm at time } t \text {, and zero } \\
\text { otherwise }\end{array}$ & \\
\hline \multicolumn{3}{|l|}{ Firm-submarket-level variables } \\
\hline$N e w F a b_{l j t}$ & $\begin{array}{l}\text { One if firm } l \text {, upon closure of its existing fab in submarket } j \text { at time } \\
t \text {, opened a new fab in submarket } j \text { at time }(t-1), t \text {, or }(t+1) \text {, } \\
\text { zero otherwise }\end{array}$ & \\
\hline TechnologyConvergence ${ }_{j t} *$ & Interaction term between TechnologyConvergence $j$ and & H3-incumbent: \\
\hline MarketConvergence $e_{j t} *$ Incumben $t_{l t}$ & MarketConvergence $_{j t}$ and Incumbent $t_{l t}$ & Negative \\
\hline \multicolumn{3}{|l|}{ Fixed effects } \\
\hline Submarket $_{j}$, Countrym & Submarket and country-level fixed effects & \\
\hline
\end{tabular}

Note: A positive (negative) prediction in the hazard model means that increasing that variable increases (decreases) the likelihood of closing fab operations.

proportional hazards model also accounts for serial correlation through the use of time-varying covariates (Allison, 1984).

The empirical model is as follows:

$$
h\left(t, Z_{i}\right)=h_{0}(t) \exp \left(Z_{i, l, j, t} \beta\right)
$$

where $h_{0}(t)$ is the unspecified baseline hazard rate, the term $Z_{i, l, j, t}$ is a matrix whose columns correspond to the explanatory variables and controls (at the fab, $i$, the firm, $l$, the submarket, $j$, and the industry levels at different times, $t$ ), and $\beta$ is a vector of coefficients. I estimate the model by using the stcox command in STATA.

\section{EMPIRICAL RESULTS}

Table 4 reports the means, standard deviations, and correlations for the variables. I note the correlation between technology convergence and market convergence $(\rho=0.463)$, which may tend to inflate the 


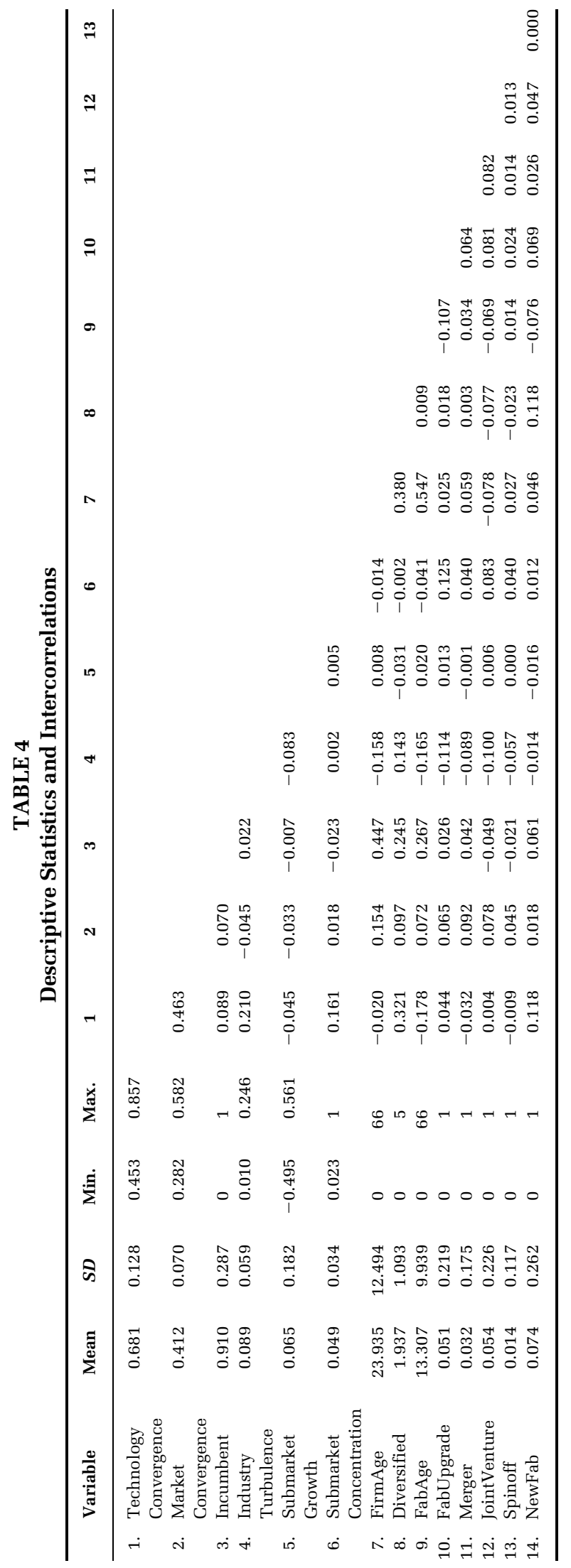


standard errors in the regressions. ${ }^{21}$ However, the variance inflation factors (VIF) for all variables are below 3.0, with the average VIF for all the covariates 1.29 , which is below the common threshold of 10 (Ryan, 1997). Furthermore, the correlation of the estimated coefficients (not the variables) is also not high (0.38) (obtained by the vce, corr command in STATA after the estimation of the Cox model, as reported in Table 5 below). Therefore, multicollinearity between the variables is not considered a significant concern.

Ireport the results of the Cox model in Table 5, where I examine the likelihood to exit or reposition due to fab closure. As I mentioned earlier, the success of industry incumbents discussed in this paper corresponds to continued fab operations in a submarket and not survival at the industry level in general (cf. Argyres et al., 2015). In the first model, I introduce only the control variables with the country fixed effects. From model 2 onward, the two main independent variables, their interaction, and the interaction of these three variables with the incumbent dummy are included in a stepwise manner. The joint Wald tests suggest that including these interactions creates statistically significant improvements in model fit $(p<.001)$. Given that I used robust estimation, it is more meaningful to draw inferences based on Wald tests rather than likelihood-ratio tests. Because the coefficients are relatively stable across models and because Model 5 offers the best fit (including the full model), I focused on that model to test Hypothesis 1-3. Model 6 runs a limited sample analysis to test Hypothesis 4, with technology and market convergence measures limited to their mean \pm 1 s.d. range, which I believe is a good proxy for a stable submarket structure to test the null effect (cf. Cashen \& Geiger, 2004).

The coefficient for TechnologyConvergence in model 5 is negative and highly significant $(\mathrm{b}=-10.86, p<$ .01): an increase only in the technology closeness of a submarket to the average of the industry decreases entrants' likelihood of exit. ${ }^{22}$ A one-standard-deviation

\footnotetext{
${ }^{21}$ In line with the literature, this correlation shows that technology and market convergence follow sequential processes (Curran \& Leker, 2011) and that technology convergence precedes market convergence (Kim, Lee, Kim, Lee, \& Suh, 2015).

${ }^{22}$ Note that in a survival regression, each coefficient corresponds to the log scale and indicates the exact impact of increasing one unit of the independent variable on the likelihood to exit while keeping the other variables fixed. Because the model is a hazard model, a positive (negative) coefficient means that increasing that variable increases (decreases) the likelihood of closing operations in a fab. Also note that a positive sign for a coefficient is the same as a hazard ratio higher than one.
}

increase only in technology closeness, exp $(-10.76$ * $0.128)=0.25(25 \%$ of the base hazard rate $)$, decreases entrants' risk of exit by $75 \%(100 \%-25 \%)$. The interaction between TechnologyConvergence and the incumbent dummy yields a highly significant positive effect: the coefficient for Incumbent * TechnologyConvergence in model 5 is $\mathrm{b}=9.534, p<.001$. In terms of effect size, a one-standard-deviation increase in technology closeness, when Incumbent is 1, exp $((-10.86+9.534) * 0.128)=0.84(84 \%$ of the base hazard rate), decreases industry incumbents' risk of repositioning through fab closure by $16 \%$. Compared with the entrants' decrease in the risk of exit from the same change $(75 \%)$, the decrease in incumbents' risk $(16 \%)$ is smaller. Thus, convergence in only technological competences is more negative for industry incumbents and less negative for entrants. This relative difference in the decrease in the risk of fab closure $(75 \%$ for entrants $-16 \%$ for industry incumbents $=59 \%$ ) is economically consequential, as fabs in my dataset reflect considerable investment (the cost of new wafer fabs and manufacturing equipment reaches $\$ 3$ billion on average). A similar result holds for MarketConvergence, as the coefficients for that variable in model 5 are negative and highly significant for entrants $(\mathrm{b}=-66.65, p<.001)$ and positive and highly significant for industry incumbents $(\mathrm{b}=20.28, p<.001)$. The sum of these coefficients, -46.37 , indicates that market convergence reduces the risk of fab closure for both entrants and incumbents, but for incumbents, this effect is weaker. Entrants fare relatively better than industry incumbents when a submarket converges toward the industry average only in customer competences. Thus, I also find support for Hypothesis 2.

To test Hypothesis 3, I examine the interaction term between TechnologyConvergence and MarketConvergence. Hypothesis 3 states that industry incumbents will fare better than entrants in submarkets that converge to the average of the industry both in technological and in customer competences. Consistent with Hypothesis 3, the coefficient for the interaction term is positive and highly significant for entrants $(b=78.53, p<.001)$ and negative and highly significant for industry incumbents $(\mathrm{b}=$ $-26.94, p<.001$ ). In terms of effect size, a onestandard-deviation increase in market closeness, when technology closeness is at its maximum (0.86), $\exp ((-66.65+0.86 * 78.53) * 0.07)=1.06(106 \%$ of the base hazard rate), increases entrants' risk of exit by $6 \%$. For industry incumbents, the same increase in market closeness, when technology closeness is at its maximum, $\exp ((20.28+0.86$ * -26.94$) * 0.07)=$ $0.82(82 \%$ of the base hazard rate), decreases 
TABLE 5

The Influence of Technology and Market Convergence on the Likelihood to Exit/Reposition through Fab Closure, Cox Hazard Model

\begin{tabular}{|c|c|c|c|c|c|c|}
\hline & (1) & (2) & (3) & (4) & (5) & (6) \\
\hline VARIABLES & & & & & H1-3 & H4 \\
\hline $\begin{array}{l}\text { TechnologyConvergence } \\
\text { (H1 - entrant) }\end{array}$ & & $\begin{array}{l}6.946^{* * *} \\
(0.694)\end{array}$ & $\begin{array}{l}-8.101^{* * *} \\
(2.705)\end{array}$ & $\begin{array}{c}-18.84 * * * \\
(2.763)\end{array}$ & $\begin{array}{c}-10.86 * * * \\
(3.244)\end{array}$ & $\begin{array}{r}-41.11 \\
(62.79)\end{array}$ \\
\hline MarketConvergence (H2 - entrant) & & $\begin{array}{l}-7.505^{* * *} \\
(1.361)\end{array}$ & $\begin{array}{c}-38.71 * * * \\
(5.964)\end{array}$ & $\begin{array}{c}-62.93 * * * \\
(4.042)\end{array}$ & $\begin{array}{c}-66.65 * * * \\
(7.759)\end{array}$ & $\begin{array}{r}-167.0 \\
(125.6)\end{array}$ \\
\hline $\begin{array}{l}\text { TechnologyConvergence * } \\
\text { MarketConvergence } \\
\text { (H3 - entrant) }\end{array}$ & & & $\begin{array}{l}40.48^{* * *} \\
(6.711)\end{array}$ & $\begin{array}{l}71.84^{* * *} \\
(6.200)\end{array}$ & $\begin{array}{l}78.53^{* * *} \\
(10.49)\end{array}$ & $\begin{array}{c}197.0 \\
(170.3)\end{array}$ \\
\hline Incumbent & & & & $\begin{array}{c}-9.355^{* * *} \\
(1.688)\end{array}$ & $\begin{array}{c}-7.238^{* * *} \\
(1.375)\end{array}$ & $\begin{array}{c}-25.10 \\
(37.77)\end{array}$ \\
\hline $\begin{array}{l}\text { Incumbent }{ }^{*} \text { TechnologyConvergence } \\
\text { (H1 - incumbent) }\end{array}$ & & & & $\begin{array}{l}11.89 * * * \\
(3.253)\end{array}$ & $\begin{array}{l}9.534^{* * *} \\
(1.992)\end{array}$ & $\begin{array}{c}39.43 \\
(53.47)\end{array}$ \\
\hline $\begin{array}{l}\text { Incumbent }{ }^{*} \text { MarketConvergence } \\
\text { (H2 - incumbent) }\end{array}$ & & & & $\begin{array}{l}26.83 * * * \\
(4.811)\end{array}$ & $\begin{array}{l}20.28 * * * \\
(3.726)\end{array}$ & $\begin{array}{l}72.35 \\
(91.73)\end{array}$ \\
\hline $\begin{array}{l}\text { Incumbent * } \\
\text { TechnologyConvergence * } \\
\text { MarketConvergence }\end{array}$ & & & & $\begin{array}{c}-34.77^{* * *} \\
(8.293)\end{array}$ & $\begin{array}{c}-26.94^{* * *} \\
(5.450)\end{array}$ & $\begin{array}{c}-113.7 \\
(130.8)\end{array}$ \\
\hline \multicolumn{7}{|l|}{ (H3 - incumbent) } \\
\hline IndustryTurbulence & $\begin{array}{l}14.76^{* * *} \\
(1.493)\end{array}$ & $\begin{array}{l}15.07^{* * *} \\
(1.065)\end{array}$ & $\begin{array}{l}14.90^{* * *} \\
(1.002)\end{array}$ & $\begin{array}{l}14.91^{* * *} \\
(0.947)\end{array}$ & $\begin{array}{l}17.86^{* * *} \\
(0.948)\end{array}$ & $\begin{array}{l}18.75^{* * *} \\
(5.266)\end{array}$ \\
\hline SubmarketGrowth & $\begin{array}{c}-0.177 \\
(0.242)\end{array}$ & $\begin{array}{c}0.157 \\
(0.241)\end{array}$ & $\begin{array}{c}0.100 \\
(0.275)\end{array}$ & $\begin{array}{c}0.0974 \\
(0.266)\end{array}$ & $\begin{array}{c}0.0620 \\
(0.223)\end{array}$ & $\begin{array}{c}0.828^{*} \\
(0.455)\end{array}$ \\
\hline SubmarketConcentration & $\begin{array}{c}-1.399 \\
(2.894)\end{array}$ & $\begin{array}{c}-10.55^{* * *} \\
(1.820)\end{array}$ & $\begin{array}{l}-9.953^{* * *} \\
(1.645)\end{array}$ & $\begin{array}{c}-10.12^{* * *} \\
(1.581)\end{array}$ & $\begin{array}{c}-7.593 * * \\
(3.819)\end{array}$ & $\begin{array}{l}-3.057^{* * *} \\
(1.187)\end{array}$ \\
\hline FirmAge & $\begin{array}{c}-0.0268 * * * \\
(0.00438)\end{array}$ & $\begin{array}{c}-0.0244^{* * *} \\
(0.00484)\end{array}$ & $\begin{array}{c}-0.0236^{* * *} \\
(0.00473)\end{array}$ & $\begin{array}{c}-0.0232^{* * *} \\
(0.00528)\end{array}$ & $\begin{array}{c}-0.0256 * * * \\
(0.00584)\end{array}$ & $\begin{array}{c}-0.0235^{*} \\
(0.0125)\end{array}$ \\
\hline Diversified & $\begin{array}{c}0.198 * * \\
(0.0864)\end{array}$ & $\begin{array}{c}0.0632 \\
(0.0772)\end{array}$ & $\begin{array}{c}0.0561 \\
(0.0777)\end{array}$ & $\begin{array}{c}0.0652 \\
(0.0800)\end{array}$ & $\begin{array}{c}0.0718 \\
(0.0803)\end{array}$ & $\begin{array}{c}0.105 \\
(0.0986)\end{array}$ \\
\hline FabAge & $\begin{array}{l}0.0353 * * * \\
(0.00234)\end{array}$ & $\begin{array}{l}0.0352 * * * \\
(0.00282)\end{array}$ & $\begin{array}{l}0.0347^{* * *} \\
(0.00261)\end{array}$ & $\begin{array}{l}0.0346 * * * \\
(0.00249)\end{array}$ & $\begin{array}{l}0.0308^{* * *} \\
(0.00455)\end{array}$ & $\begin{array}{c}0.0215 \\
(0.0139)\end{array}$ \\
\hline FabUpgrade & $\begin{array}{c}-0.119 \\
(0.0995)\end{array}$ & $\begin{array}{c}-0.242^{* *} \\
(0.0991)\end{array}$ & $\begin{array}{c}-0.245^{* *} \\
(0.0978)\end{array}$ & $\begin{array}{c}-0.242^{* *} \\
(0.0980)\end{array}$ & $\begin{array}{c}-0.264^{* *} \\
(0.103)\end{array}$ & $\begin{array}{c}-0.601 * * \\
(0.260)\end{array}$ \\
\hline Merger & $\begin{array}{c}0.0558 \\
(0.112)\end{array}$ & $\begin{array}{c}0.0518 \\
(0.109)\end{array}$ & $\begin{array}{c}0.0536 \\
(0.0901)\end{array}$ & $\begin{array}{c}0.0516 \\
(0.0896)\end{array}$ & $\begin{array}{c}0.0662 \\
(0.106)\end{array}$ & $\begin{array}{c}0.170 \\
(0.190)\end{array}$ \\
\hline JointVenture & $\begin{array}{l}0.230 * * * \\
(0.0774)\end{array}$ & $\begin{array}{c}0.0146 \\
(0.142)\end{array}$ & $\begin{array}{c}0.0142 \\
(0.141)\end{array}$ & $\begin{array}{l}0.00621 \\
(0.140)\end{array}$ & $\begin{array}{c}-0.00175 \\
(0.147)\end{array}$ & $\begin{array}{c}0.0561 \\
(0.0405)\end{array}$ \\
\hline Spinoff & $\begin{array}{c}-0.0902 \\
(0.261)\end{array}$ & $\begin{array}{c}-0.172 \\
(0.247)\end{array}$ & $\begin{array}{c}-0.186 \\
(0.239)\end{array}$ & $\begin{array}{c}-0.169 \\
(0.235)\end{array}$ & $\begin{array}{c}-0.126 \\
(0.225)\end{array}$ & $\begin{array}{c}0.393 \\
(0.470)\end{array}$ \\
\hline Newfab & $\begin{array}{l}1.836^{* * *} \\
(0.189)\end{array}$ & $\begin{array}{l}1.703^{* * *} \\
(0.151)\end{array}$ & $\begin{array}{l}1.717^{* * *} \\
(0.145)\end{array}$ & $\begin{array}{l}1.723^{* * *} \\
(0.149)\end{array}$ & $\begin{array}{l}1.746^{* * *} \\
(0.164)\end{array}$ & $\begin{array}{l}2.112^{* * *} \\
(0.120)\end{array}$ \\
\hline Number of observations & 15559 & 15559 & 15559 & 15559 & 15559 & 4568 \\
\hline Number of failures & 1128 & 1128 & 1128 & 1128 & 1128 & 303 \\
\hline Number of subjects & 1565 & 1565 & 1565 & 1565 & 1565 & 966 \\
\hline Country Fixed Effects & YES & YES & YES & YES & YES & YES \\
\hline Submarket Fixed Effects & NO & NO & NO & NO & YES & YES \\
\hline Log pseudolikelihood & -7490 & -7373 & -7359 & -7356 & -7311 & -1584 \\
\hline Wald $\chi^{2}(d f)$ & $5881.51(5) * * *$ & $62.43(4) * * *$ & $62.15(4) * * *$ & $158.69(4) * * *$ & $80.90(4) * * *$ & $2.92(3)$ \\
\hline $\begin{array}{l}\text { Wald test of incremental } \\
\text { addition to previous model ( } d f \text { ) }\end{array}$ & & $110.84(2) * * *$ & $36.39(1) * * *$ & $197.98(4) * * *$ & $445.96(4) * * *$ & $\mathrm{n} / \mathrm{a}$ \\
\hline
\end{tabular}

\footnotetext{
${ }^{*} p<0.1$

${ }^{* *} p<0.05$

$* * * p<0.01$
}

Note: Robust standard errors in parentheses 
industry incumbents' risk of fab closure by $18 \%$. This range of variation in the risk of fab closure (from +6 to $-18 \%$ ) is economically consequential because of the high costs of opening a new fab (Uzunca \& Cassiman, 2017).

Model 6 tests a limited sample analysis for testing Hypothesis 4. I limited technology and market closeness to their mean \pm 1 s.d. range to test the lack of effect of non-convergence (cf. Cashen \& Geiger, 2004). The results show that while the direction of the above-discussed coefficients remained the same, only their significance levels entirely disappeared. Because the control variables sustain their significance levels from other models, the disappearance of the significance levels in main covariates is not due to having fewer observations. Thus, Hypothesis 4 is also supported: there is a null effect on how entrants and incumbents fare in submarkets that do not converge in technological or in customer competences.

The remaining results in Table 5 point to several other factors influencing a firm's exit or repositioning through fab closure. Consistent with prior research, I find that industry turbulence-the sum of gross entry and gross exit rates-has a strong positive effect on fab closure (Sutton, 1997). I also find that the concentration of firms in a submarket exhibits a negative relationship with the hazard of fab closure in that submarket. In concentrated industries, many firms may be protected from competition, and consequently, fab closure or exit rates are smaller (Caves, 1998). Similar to what King and Tucci (2002) theorize and find about static and dynamic (transformational) experience, I also find that firms benefit from static experience (the coefficient for FirmAge is $\mathrm{b}=-0.025, p<.001$ ); in other words, experience does not necessarily lead to inertia. For the "transformational" experience, King and Tucci construct a variable (prior transition experience) that measures whether the firm had previously entered a submarket other than its original one. For this, I added a control variable, Diversified $d_{l t}$, which measures the number of submarkets in which firm $l$ owns at least one fab at time $t$. This variable captures second-order competences in a similar way as King and Tucci capture experience gained from entering different submarkets. As they theorize and find, I also find that firms with more diversified product portfolios-that is, firms with more transformational experience-do not necessarily benefit from it (the coefficient for Diversified is $\mathrm{b}=0.072, p=0.372$ ). As expected, FabAge's positive and significant effect reflects that older fabs are more likely to be closed, and FabUpgrade's negative and significant effect captures that mature fabs undergoing an upgrade or expansion are less likely to cease their operations. Maybe the most important among all controls, NewFab, which captures whether a firm abandons an old fab and builds a new one to shift production to newer, more efficient plants because its production machinery is outdated, is positive and highly significant. I created this variable in a conservative way to cover a wide range of periods; $N e w F a b_{l j t}=1$ if firm l, upon closure of its existing fab in submarket $j$ at time $t$, opened a new fab in submarket $j$ at time $(t-1)$, $t$, or $(t+1)$ and 0 otherwise. Other factors do not have a significant effect on firms' fab closure.

\section{DISCUSSION AND CONCLUSION}

In this paper, I characterize the competence-based view of submarket industry evolution. I build a new typology and a framework based on technology and market convergence between submarkets and shed further light on when incumbents dominate entrants or are disrupted by them. I test the hypotheses on a panel dataset including over 17,000 observations in the global semiconductor manufacturing industry and find support for the theoretical arguments. This study makes several contributions to the industry evolution literature by characterizing how changes in other submarkets affect industry incumbents' and entrants' chances of success in a submarket.

While prior empirical work on the homogenization of industry structures has noted the importance of technology-related explanations (Klepper, 1996; Suarez \& Utterback, 1995), the effect of market-related resources and competences (and the complementary power of the two) on incumbent-entrant dynamics, as reflected in their likelihood to exit or reposition in different submarkets, has not been explored. Focusing on submarket dynamics (including a better industry definition based on them), I argue that the evolution of the heterogeneous structure within an industry, i.e., how submarkets converge to each other toward a homogeneous industry structure, plays a significant role in explaining these dynamics.

Submarkets put a powerful restriction on the patterns of firms' learning, competences, and behavior, and the organization of innovative, manufacturing, and selling activities (Sutton, 1998). However, it is seldom used in strategic management to denote the boundaries of knowledge growth and of exploitability of competences within an industry. In that sense, industry convergence is seldom clearly defined and empirically studied by strategy scholars. Analyzing the semiconductor manufacturing industry at 
the submarket level allows me to shed new light on the logic of structural changes in the industry over time. Rapid and sustained technological innovation has led semiconductors to continuously become better, faster, and cheaper, providing opportunities for both incumbent and entrant firms to focus on new areas of growth. Consequently, new submarkets using different process technologies and/or different products with distinct functionalities have emerged (Chesbrough, 2003). These differences on the technology and market sides permit increased specialization based on submarkets incubating disruptive technologies, which would have failed had they occurred in a more homogeneous industry structure or at the fringe of submarkets dominated by industry incumbents (Bresnahan \& Greenstein, 1999). I show that, although the semiconductor manufacturing industry shows signs of maturity at the industry level, closer examination of submarkets shows that the industry is continuously open to disruptions from both the technology and market sides. Thus, the pace of evolution with regard to submarkets' positions in the same industry affects the ability of industry incumbents to respond to possible threats. As one can see, this theoretical argument for incumbents' disruption by entrants is different from Christensen's (1997) view, which is often criticized for being based on the myopic behavior of industry incumbents that miss opportunities because they favor current markets and customers over new ones. The argument developed here for the occurrence of disruption is based on a failure to possess the competences to produce and sell products in different submarkets. ${ }^{23}$ Thus, one of the key elements of the theory of disruptive innovation-that "incumbents have the capability to respond but fail to exploit" (King \& Baatartogtokh, 2015)—does not apply to the theory and findings of this paper. The main mechanism for disruption is the incompetence-not myopia-of industry incumbents in selling their products to other types of customers. This argument is more in line with what Priem, Sali, and Carr (2012: 352) state, "Altogether, these works show how an incumbent's inability to identify future demand can cause failures in

\footnotetext{
${ }^{23}$ A recent article in The Economist confirms this view: "he (Christensen) should be treated as one voice among many. There are types of disruptive innovation other than the one he champions. Insurgents can revolutionize old industries by using new technologies, but established companies can use their superior war chests and management skills to invade adjacent industries" (The Economist, 2015).
}

the face of disruptive technology changes, thereby challenging the universality of Christensen's innovator's dilemma and providing practical implications for innovation management."

A challenge in trying to understand the occurrence of shakeouts is that it is difficult to untangle the conditions under which industries converge to homogeneous structures-where one group of firms grows and takes the lead by reinforcing industrial leadership-from the conditions under which industries remain segmented and heterogeneous, where no one group of firms dominates and leadership often changes (Bonaccorsi \& Giuri, 2000; Klepper \& Thompson, 2006). The ILC model's arguments regarding convergence and severe shakeouts due to a change in incentives from product to process innovation does not leave any room for potential disruptions by entrants. By "treating industries as homogeneous" (Knudsen et al., 2014), the ILC literature effectively assumes away the likelihood that the same industry can take distinct evolutionary paths through different submarkets (Klepper \& Thompson, 2006: 875). The nature of this paper's setting allows me to take a major step toward disentangling the conditions under which alternative industry evolution patterns can be observed. The descriptive data suggested that the memory and logic submarkets, where industry incumbents such as Samsung and Intel operate, experience consolidation, in line with the monolithic view of industry evolution (Klepper, 1996). Quantitative analysis of the likelihood of fab closure reinforced the conclusions of the descriptive analysis, suggesting that entrants in submarkets that converge toward the industry average both in technological and in customer competences indeed have a lower likelihood of survival. Because of consolidation, manufacturers in these submarkets are trimmed to a handful of firms. However, in the analog, discrete, and MEMS submarkets, these patterns do not hold, as the companies in these submarkets use different process technologies and produce different products that are sold to different customers. Thus, the evolution of the semiconductor submarket structure leads to the existence of two types of areas within the same industry: (1) consolidated areas, where product standardization leads to scale economies and subsequently to consolidation into a stable oligopolistic industry structure à la Klepper (through a shakeout) dominated by early incumbent leaders, and (2) areas characterized by Schumpeterian competition, which supports, à la Sutton, the survival of entrants against industry incumbents in terms of producing 
and/or selling products in different submarkets. Therefore, a fundamental attribute of the theorythat different industry evolution patterns can be observed through the evolution of submarket structure from the technology and market sides-provides novel insight into the question of "why shakeouts do not occur" (Bonaccorsi \& Giuri, 2000; Buenstorf, 2007; Cabral, 2012).

My concepts of technology and market closeness also have implications for reconceiving industry relatedness in diversification (including M\&A) research. Though there is no univocal agreement about the measurements of relatedness (Robin \& Wiersema, 2003), the way I conceptualize and measure convergence of an industry's technologies and markets can be used by various streams of literature measuring corporate diversification (Robin \& Wiersema, 2003) or knowledge and technology relatedness (Breschi, Lissoni, \& Malerba, 2003). Similarly, the repositioning of industry incumbents as a strategic response to disruptions (Argyres et al., 2015; de Figueiredo \& Silverman, 2007) deserves more attention from strategy and innovation scholars. Studies must consider not only survival as a potential consequence of disruption but also a broader range of incumbent outcomes-such as major changes in an incumbent's performance (Gans, 2016).

The theory that is developed and tested here is applicable to all industries, regardless of whether they are segmented into independent submarkets. Industries comprising many submarkets, such as the semiconductor manufacturing industry, may provide entrants with sufficient space to avoid head-on competition with industry incumbents. By remaining sufficiently distant from submarkets dominated by large and cost-efficient incumbents, entrants can have sufficient time and space to gain a foothold in the industry and can avoid elimination due to consolidation. The key implication for firms is the need to understand their differentiating factors at the submarket level (technology or market). Consider the transportation industry. Given the threat by Uber, the world's most valuable startup, why can't incumbent carmakers dominate the personal transport industry? Carmakers lack Uber's experience as a service provider or its deep knowledge of demand patterns and customer behavior. This phenomenon can be explained by the non-convergence of customer competences. When there is insufficient space to hide, industry incumbents eventually convert the industry into one large, homogeneous market, such as in the U.S. automotive, tire, and TV industries. For industry incumbents, it is important to be responsive and proactive when firms that have different competences enter the industry.

In this regard, it is important to think about how managers see the evolution of the submarkets in their industry. The Smith Corona case (cf. Danneels, 2011) provides a great example, as the CEO believed that PCs and word processors or typewriters were in fundamentally different markets and would continue to coexist. However, these submarkets converged. This study has broader implications for incumbents, highlighting the need to manage the tension between continuing growth in their own submarkets and exploring new production technologies and new product functionalities (Christensen, 1997). The literature is deliberate when claiming the power of entrants in displacing incumbents. For entrants, "success" is defined as gaining some initial foothold in the industry (Knudsen et al., 2014; Malerba \& Orsenigo, 2002). While acknowledging this fact, I confirm in this paper that industry incumbents and entrants experience opposite effects from the evolution of the submarket structure, i.e., entrants' "gaining foothold in the industry" is actually related to the repositioning of incumbent firms.

Overall, this paper can be considered a step toward advancing research examining the effect of industry structures on competitive dynamics between industry incumbents and entrants. The extensive illustration of submarkets S1 and S2 in the theoretical development could be converted into a mathematical model (à la Klepper, 1996) or a simulation (à la Harrison, 2004). This paper also complements the current monolithic view to render it a more general theory of industry evolution that can explain disruption by entrants. Future work can further improve the framework developed here to reconcile the complementary theories of Steve Klepper's dominance of incumbents through severe shakeouts and Clayton Christensen's disruption by entrants.

\section{REFERENCES}

Abernathy, W. J., \& Clark, K. B. 1985. Innovation: Mapping the winds of creative destruction. Research Policy, 14: 3-22.

Adner, R. 2002. When are technologies disruptive: A demand-based view of the emergence of competition. Strategic Management Journal, 23: 667-688.

Adner, R., \& Levinthal, D. 2001. Demand heterogeneity and technology evolution: Implications for product and pro cess innovation. Management Science, 47: 611-628. 
Adner, R., \& Snow, D. 2010. Old technology responses to new technology threats: Demand heterogeneity and technology retreats. Industrial and Corporate Change, 19: $1655-1675$.

Adner, R., \& Zemsky, P. 2005. Disruptive technologies and the emergence of competition. The Rand Journal of Economics, 36: 229-254.

Agarwal, R., Sarkar, M. B., \& Echambadi, R. 2002. The conditioning effect of time on firm survival: An industry life cycle approach. Academy of Management Journal, 45: 971-994.

Allison, P. D. 1984. Event history analysis. Thousand Oaks, CA: Sage.

Anderson, P., \& Tushman, M. 1990. Technological discontinuities and dominant designs: A cyclical model of technological change. Administrative Science Quarterly, 35: 604-635.

Ansari, S., \& Krop, P. 2012. Incumbent performance in the face of a radical innovation: Towards a framework for incumbent challenger dynamics. Research Policy, 41: 1357-1374.

Argyres, N., Bigelow, L., \& Nickerson, J. A. 2015. Dominant designs, innovation shocks, and the follower's dilemma. Strategic Management Journal, 36: 216-234.

Barroso, A., Giarratana, M. S., Reis, S., \& Sorenson, O. 2016. Crowding, satiation, and saturation: The days of television series' lives. Strategic Management Journal, 37: 565-585.

Benner, M., \& Tripsas, M. 2012. The influence of prior industry affiliation on framing in nascent industries: The evolution of digital cameras. Strategic Management Journal, 33: 277-302.

Bhaskarabhatla, A., \& Klepper, S. 2014. Latent submarket dynamics and industry evolution: Lessons from the U.S. laser industry. Industrial and Corporate Change, 23: 1381-1415.

Bloom, N., Schankerman, M., \& Van Reenen, J. 2013. Identifying technology spillovers and product market rivalry. Econometrica, 81: 1347-1393.

Boeker, W. 1989. Strategic change: The effects of founding and history. Academy of Management Journal, 32: 489-515.

Bonaccorsi, A., \& Giuri, P. 2000. When shakeout doesn't occur: The evolution of the turboprop engine industry. Research Policy, 29: 847-870.

Breschi, S., Lissoni, F., \& Malerba, F. 2003. Knowledgerelatedness in firm technological diversification. Research Policy, 32: 69-87.

Bresnahan, T. F., \& Greenstein, S. 1999. Technological competition and the structure of the computer industry. The Journal of Industrial Economics, 47: $1-40$.
Bryce, D. J., \& Winter, S. G. 2009. A general interindustry relatedness index. Management Science, 55: 1570-1585.

Buenstorf, G. 2007. Evolution on the shoulders of giants: Entrepreneurship and firm survival in the German laser industry. Review of Industrial Organization, 30: 179-202.

Buenstorf, G., \& Klepper, S. 2010. Submarket dynamics and innovation: The case of the U.S. tire industry. Industrial and Corporate Change, 19: 1563-1587.

Cabral, L. 2012. Technology uncertainty, sunk costs, and industry shakeout. Industrial and Corporate Change, 21: 539-552.

Cashen, L. H., \& Geiger, S. W. 2004. Statistical power and the testing of null hypotheses: A review of contemporary management research and recommendations for future studies. Organizational Research Methods, 7: 151-167.

Caves, R. E. 1998. Industrial organization and new findings on the turnover and mobility of firms. Journal of Economic Literature, 36: 1947-1982.

Charitou, C., \& Markides, C. 2003. Responses to disruptive strategic innovation. MIT Sloan Management Review, 44: 55-64.

Chesbrough, H. 2003. Environmental influences upon firm entry into new submarkets: Evidence from the worldwide hard disk drive industry. Research Policy, 32: 659-678.

Christensen, C. M. 1997. The innovator's dilemma, Boston, MA: Harvard Business School Press.

Christensen, C. M. 2006. The ongoing process of building a theory of disruption. Journal of Product Innovation Management, 23: 39-55.

Christensen, C. M., Anthony, S., \& Roth, E. 2004. Seeing what's next: Using the theories of innovation to predict industry change. Boston, MA: Harvard Business School Press.

Christensen, C. M., \& Bower, J. L. 1996. Customer power, strategic investment, and the failure of leading firms. Strategic Management Journal, 17: 197-218.

Christensen, C. M., Raynor, M., \& McDonald, R. 2015. What is disruptive innovation? Harvard Business Review, 93: 44-53.

Clark, K. B. 1985. The interaction of design hierarchies and market concepts in technological evolution. Research Policy, 14: 235-251.

Cleves, M., Gutierrez, R. G., Gould, W., \& Marchenko, Y. V. 2004. An introduction to survival analysis using Stata. College Station, TX: Stata Press.

Coad, A., \& Guenther, C. 2013. Diversification patterns and survival as firms mature. Small Business Economics, 41: 633-649. 
Curran, C. S., \& Leker, J. 2011. Patent indicators for monitoring convergence - examples from NFF and ICT. Technological Forecasting and Social Change, 78: 256-273.

Danneels, E. 2002. The dynamics of product innovation and firm competences. Strategic Management Journal, 23: 1095-1121.

Danneels, E. 2003. Tight-loose coupling with customers: The enactment of customer orientation. Strategic Management Journal, 24: 559-576.

Danneels, E. 2004. Disruptive technology reconsidered: A critique and research agenda. Journal of Product Innovation Management, 21: 246-258.

Danneels, E. 2011. Trying to become a different type of company: Dynamic capability at Smith Corona. Strategic Management Journal, 32: 1-31.

Dewar, R. D., \& Dutton, J. E. 1986. The adoption of radical and incremental innovations: An empirical analysis. Management. Science, 32: 1422-1433.

de Figueiredo, J. M., \& Silverman, B. S. 2007. Churn baby churn: Strategic dynamics among dominant and fringe firms in a segmented industry. Management Science, 53: 632-650.

Dosi, G. 1982. Technological paradigms and technological trajectories: A suggested interpretation of the determinants and directions of technical change. Research Policy, 11: 147-162.

Doty, D. H., \& Glick, W. H. 1994. Typologies as a unique form of theory building: Toward improved understanding and modeling. Academy of Management Review, 19: 230-251.

Dunne, T., Roberts, M., \& Samuelson, L. 1988. Patterns of firm entry and exit in U.S. manufacturing industries. The Rand Journal of Economics, 19: 495-515.

Economist. 2015. Disrupting Mr Disrupter. www.economist. com/news/business/21679179-clay-christensen-shouldnot-be-given-last-word-disruptive-innovation-disruptingmr. Accessed on May 15, 2016.

Eisenhardt, K. M., \& Schoonhoven, C. B. 1990. Organizational growth: Linking founding team, strategy, environment, and growth among U.S. semiconductor ventures, 1978-1988. Administrative Science Quarterly, 35: 504-529.

Ferrier, W. J., Smith, K. G., \& Grimm, C. M. 1999. The role of competitive action in market share erosion and industry dethronement: A study of industry leaders and challengers. Academy of Management Journal, 42: 372-388.

Foster, R. N. 1986. Innovation: The attacker's advantage. New York: Summit Books.

Gans, J. S. 2016. 2016 keep calm and manage disruption. MIT Sloan Management Review, 22 February.
Geroski, P. 1998. Thinking creatively about markets. International Journal of Industrial Organization, 16: $677-698$.

Giustiziero, G., \& Wu, B. 2016. Creative construction in a Schumpeterian environment: The duality of learning and competition. Working paper.

Gort, M., \& Klepper, S. 1982. Time paths in the diffusion of product innovations. Economic Journal (London), 92: 630-653.

Greenstein, S., \& Khanna, T. 1997. What does industry convergence mean. In D. Yoffie (Ed.), Competing in the age of digital convergence. Boston, MA: Harvard Business School Press.

Guenther, C. 2009. Towards automated manufacturingcreation, fusion and destruction of submarkets in the German machine tool market, paper presented at the DRUID Summer Conference Copenhagen, June 17-19.

Hannan, M. T., \& Freeman, J. 1984. Structural inertia and organizational change. American Sociological Review, 49: 149-164.

Harrison, J. 2004. Models of growth in organizational ecology: A simulation assessment. Industrial and Corporate Change, 13: 243-280.

Helfat, C., \& Campo-Rembado, M. 2016. Integrative capabilities, vertical integration, and innovation over successive technology lifecycles. Organization Science, 27: $249-264$

Henderson, R. M. 1993. Underinvestment and incompetence as responses to radical innovation: Evidence from the photolithographic alignment equipment industry. The Rand Journal of Economics, 24: 248270.

Henderson, R. M., \& Clark, K. B. 1990. Architectural innovation: The reconfiguration of existing product technologies and the failure of established firms. Administrative Science Quarterly, 35: 9-30.

Henderson, R, \& Cockburn, I. 1994. Measuring competence? Exploring firm effects in pharmaceutical research. Strategic Management Journal, Winter Special Issue 15: $63-84$.

Hill, C. W. L., \& Rothaermel, F. T. 2003. The performance of incumbent firms in the face of radical technological innovation. Academy of Management Review, 28: 257-274.

Jaffe, A. 1986. Technological opportunity and spillovers of R\&D: Evidence from firms' patents, profits and market value. The American Economic Review, 76: 9841001.

Jiang, L., Tan, J., \& Thursby, M. 2011. Incumbent firm invention in emerging fields: Evidence from the semiconductor industry. Strategic Management Journal, 32: $55-75$. 
Jovanovic, B., \& MacDonald, G. M. 1994. The life cycle of a competitive industry. Journal of Political Economy, 102: 322-347.

Kapoor, R. 2013. Persistence of integration in the face of specialization: How firms navigated the winds of disintegration and shaped the architecture of the semiconductor industry. Organization Science, 24: 1195-1213.

Keller, G., \& Rady, S. 1999. Optimal experimentation in a changing environment. The Review of Economic Studies, 66: 475-507.

Kim, N., Lee, H., Kim, W., Lee, H., \& Suh, J. H. 2015. Dynamic patterns of industry convergence: Evidence from a large amount of unstructured data. Research Policy, 44: 1734-1748.

King, A. A., \& Baatartogtokh, B. 2015. How useful is the theory of disruptive innovation? MIT Sloan Management Review, 57: 77-90.

King, A. A., \& Tucci, C. 2002. Incumbent entry into new market niches: The role of experience and managerial choice in the creation of dynamic capabilities. Management Science, 48: 171-186.

Klepper, S. 1996. Entry, exit, growth, and innovation over the product life cycle. The American Economic Review, 86: 562-583.

Klepper, S. 1997. Industry life cycles. Industrial and Corporate Change, 6: 145-182.

Klepper, S., \& Simons, K. L. 1997. Technological extinctions of industrial firms: An inquiry into their nature and causes. Industrial and Corporate Change, 6: 379460.

Klepper, S., \& Thompson, P. 2006. Submarkets and the evolution of market structure. The Rand Journal of Economics, 37: 861-886.

Knudsen, T., Levinthal, D. A., \& Winter, S. G. 2014. Hidden but in plain sight: The role of scale adjustment in industry dynamics. Strategic Management Journal, 35 : 1569-1584.

Leachman, R. C., \& Leachman, C. H. 1999. Trends in worldwide semiconductor fabrication capacity. Competitive Semiconductor Manufacturing Program Report, CSM-48, University of California, Los Angeles.

Leonard-Barton, D. 1992. Core capabilities and core rigidities: A paradox in managing new product development. Strategic Management Journal, 13: 111-125.

Lepore, J. 2014. The disruption machine: What the gospel of innovation gets wrong. The New Yorker, June 23.

Lei, D. T. 2000. Industry evolution and competence development: The imperatives of technological convergence. International Journal of Technology Management, 19: 699-738.
Li, H., \& Atuahene-Gima, K. 2001. Product innovation strategy and the performance of new technology ventures in China. Academy of Management Journal, 44: 1123-1134.

Malerba, F., \& Orsenigo, L. 2002. Innovation and market structure in the dynamics of the pharmaceutical industry and biotechnology: Towards a history-friendly model. Industrial and Corporate Change, 11: 667-703.

McCann, J. E. 1991. Patterns of growth, competitive technology, and financial strategies in young ventures. Journal of Business Venturing, 6: 189-208.

Mitchell, W. 1992. Are more good things better, or will technical and market capabilities conflict when a firm expands? Industrial and Corporate Change, 1: 327346.

Mitchell, M., \& Skrzypacz, A. 2015. A theory of market pioneers, dynamic capabilities, and industry evolution. Management Science, 61: 1598-1614.

Morita, J., Lee, T., \& Mowday, R. 1993. The regressionanalog approach to survival analysis: A selected application to turnover research. Academy of Management Journal, 36: 1430-1464.

Péli, G. 2009. Fit by founding, fit by adaptation: Reconciling conflicting organization theories with logical formalization. Academy of Management Review, 34: 343-360.

Porter, M. E. 1980. Competitive strategy: Techniques for analyzing industries and competitors. New York: Free Press.

Posen, H. E., \& Levinthal, D. A. 2012. Chasing a moving target: Exploitation and exploration in dynamic environments. Management Science, 58: 587-601.

Priem, R. L. 2007. A consumer perspective on value creation. Academy of Management Review, 32: 219-235.

Priem, R. L., Sali, L., \& Carr, J. C. 2012. Insights and new directions from demand-side approaches to technology innovation, entrepreneurship, and strategic management research. Journal of Management, 38: 346-374.

Robin, J. A., \& Wiersema, C. F. 2003. The measurement of corporate portfolio strategy: Analysis of the content validity of related diversification indexes. Strategic Management Journal, 24: 39-59.

Ross, J. M., \& Sharapov, D. 2015. When the leader follows: Avoiding dethronement through imitation. Academy of Management Journal, 58: 658-679.

Rothaermel, F. T., \& Hill, C. W. 2005. Technological discontinuities and complementary assets: A longitudinal study of industry and firm performance. Organization Science, 16: 52-70.

Ryan, T. 1997. Modern regression analysis. New York: John Wiley and Sons. 
Sanderson, S. W., \& Simons, K. L. 2014. Light emitting diodes and the lighting revolution: The emergence of a solid-state lighting industry. Research Policy, 43: 1730-1746.

Schumpeter, J. A. 1994. Capitalism, socialism \& democracy (5th edn). New York: Routledge.

Sood, A., \& Tellis, G. J. 2011. Demystifying disruption: A new model for understanding and predicting disruptive technologies. Marketing Science, 30: 339-354.

Sosa, M. L. 2009. Application-specific R\&D capabilities and the advantage of incumbents: Evidence from the anticancer drug market. Management Science, 55: 1409-1422.

Sosa, M. L. 2011. From old competence destruction to new competence access: Evidence from the comparison of two discontinuities in anticancer drug discovery. Organization Science, 22: 1500-1516.

Sosa, M. L. 2013. Decoupling market incumbency from organizational prehistory: Locating the real sources of competitive advantage in R\&D for radical innovation. Strategic Management Journal, 34: 245-255.

Stephens, D. W. 1991. Change, regularity and value in the evolution of animal learning. Behavioral Ecology, 2: 77-78.

Stieglitz, N. 2003. Digital dynamics and types of industry convergence: The evolution of the handheld computers market. The Industrial Dynamics of the New Digital Economy, 20: 179-208.

Stieglitz, N., Knudsen, T., \& Becker, M. C. 2016. Adaptation and inertia in dynamic environments. Strategic Management Journal, 37: 1854-1864.

Suarez, F. F., Grodal, S., \& Gotsopoulos, A. 2015. Perfect timing? Dominant category, dominant design, and the window of opportunity for firm entry. Strategic Management Journal, 36: 437-448.

Suarez, F. F., \& Utterback, J. M. 1995. Dominant designs and the survival of firms. Strategic Management Journal, 16: 415-430.

Sutton, J. 1997. Gibrat's legacy. Journal of Economic Literature, 35: 40-59.

Sutton, J. 1998. Technology and market structure, Cambridge, MA: MIT Press.

Teece, D. 1986. Profiting from technological innovation: Implications for integration, collaboration, licensing, and public policy. Research Policy, 15: 286-305.

Thompson, P. 2005. Selection and firm survival: Evidence from the shipbuilding industry, 1825-1914. The Review of Economics and Statistics, 87: 26-36.
Tripsas, M. 1997. Unraveling the process of creative destruction: Complementary assets and incumbent survival in the typesetter industry. Strategic Management Journal, 18: 119-142.

Tripsas, M. 2008. Customer preference discontinuities: A trigger for radical technological change. Managerial and Decision Economics, 29: 79-97.

Tuma, N., \& Hannan, M. 1984. Social dynamics: Models and methods. New York: Academic Press.

Tushman, M. L., \& Anderson, P. 1986. Technological discontinuities and organizational environments. Administrative Science Quarterly, 31: 439-465.

Utterback, J. M. 1994. Mastering the dynamics of innovation. Boston, MA: Harvard Business School Press.

Utterback, J. M., \& Abernathy, W. J. 1975. A dynamic model of process and product innovation. Omega, 3: 639656.

Utterback, J. M., \& Suarez, F. F. 1993. Innovation, competition, and industry structure. Research Policy, 22: $1-21$.

Uzunca, B., \& Cassiman, B. 2017. Entry diversion: Entry barriers to divert submarket entry. Working Paper, The Utrecht University School of Economics, Utrecht.

Wang, R. D., \& Shaver, J. M. 2014. Competition-driven repositioning. Strategic Management Journal, 35: 1585-1604.

Wang, R. D., \& Shaver, J. M. 2016. The multifaceted nature of competitive response: Repositioning and new product launch as joint response to competition strategy science. Strategy Science 1: 148-162.

Windrum, P., \& Birchenhall, C. 1998. Is product life cycle theory a special case? Dominant designs and the emergence of market niches through coevolutionarylearning. Structural Change and Economic Dynamics, 9: 109-134.

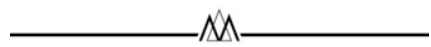

Bilgehan Uzunca (b.uzunca@uu.nl) is an assistant professor of strategic management at Utrecht University School of Economics. He received his $\mathrm{PhD}$ in management from IESE Business School, Barcelona, Spain. His research focuses on the effect of relations and strategic interactions between heterogeneous industry landscapes, such as submarkets, or ecosystem niches on entry/exit, performance, and survival of firms. 